\title{
استخلاه طريقة أشجار راش للكشف عن الأداء التفاضلي لفقرات الامتحان الوطني في الرياضيات للصف الرابع الأساسي في الأردن
}

\author{
* آيات أبو مسرة و يوسف السوالمة
}

\section{Doi: //10.47015/17.1.8}

تاريخ قبوله: 2020/4/29

تاريخ تسلم البحث: 2019/12/31

Using Rasch Trees Method to Detect Differential Item

Functioning in the Jordanian National Test in Mathematics for Fourth Graders

Ayat Abu Masarrah and Yousef Al-Sawalmeh, Yarmouk

University, Jordan.

Abstract: The present study aimed to use Rasch trees method to detect differential item functioning (DIF) in the Jordanian National Test to control educational quality in mathematics, for fourth graders, according to gender, school location, supervising authority, and test modality, as well as to investigate the effect of sample size on the method. The study population consisted of (31136) fourth graders' responses on (25) multiple choice items fitted with the Rasch model. Rasch trees method was used to analyze (1500) randomly selected responses. The results indicated that there is DIF in terms of gender only. Eight items, representing (32\%) of the test items, were detected to have DIF, five in favor of males and three in favor of females. The results showed that Rasch trees model is sensitive to sample size, where the DIF rate increased as the sample size increased.

(Keywords: Rasch Trees, Recursive Partitioning, National Test, Differential Functioning, Item Bias)

وانطلاقًا من أن تحصيل الطلبة يُعـد مؤشـرًا أساسيًا لتقييمم نوعيـة

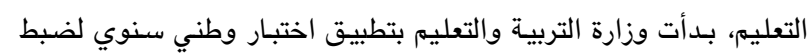

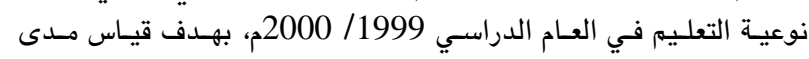

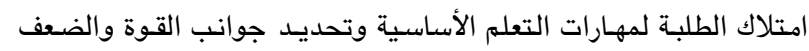

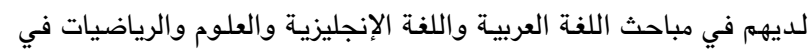
الصفوف الرابع والثامن والعاشـر الأساسية ( Jordanian Ministry of

. (Education, 2018

وزاد الاهتمام بهذه الاختبارات بعد عام 2012 لتحاكي الاختبارات

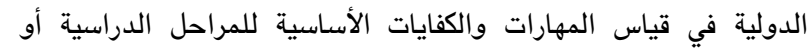

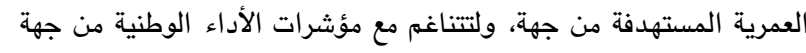

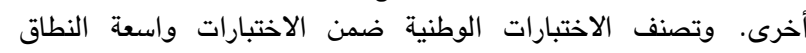
(Large-scale Assessment)

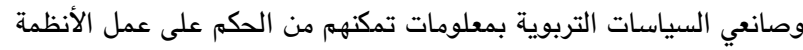

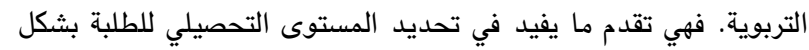

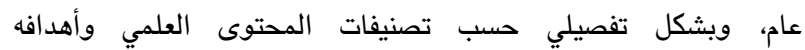
بمستوياتها المختلفة (Alpursan, 2013).

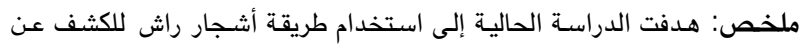

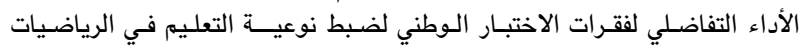

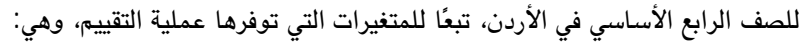

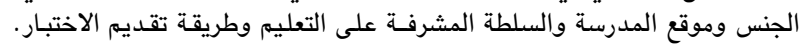

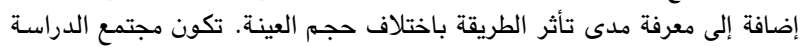

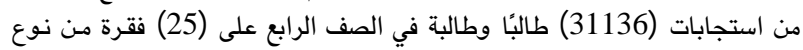

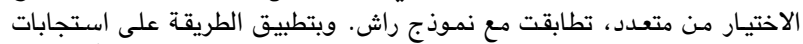

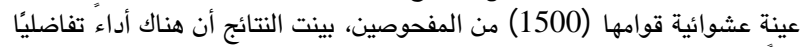

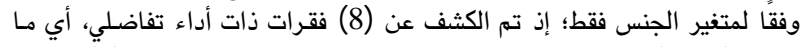

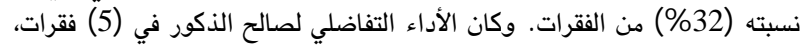

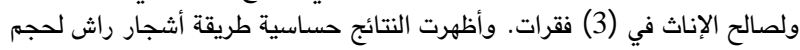

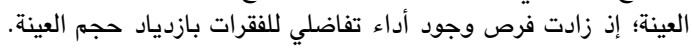
(الكلمـات المفتاحيـة: أشـجار راش، التقسيم المتكرر، الاختبـار الوطني، الأداء

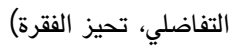

مقدمـة: تولي وزارة التربيـة والتعليم الأردنيـة الرياضيات اهتمامًا

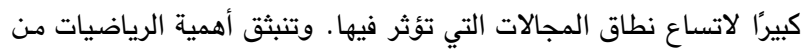

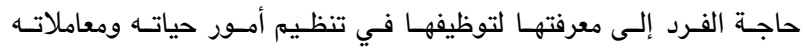

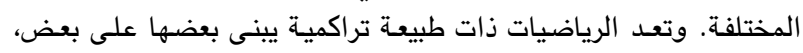

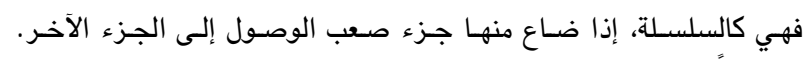

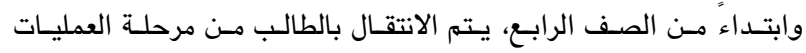

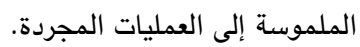

وتعد مراقبة مستوى مخرجات النظام التربوي وتقييمه من المهمات

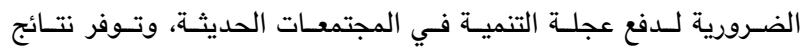

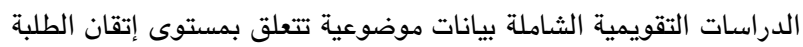

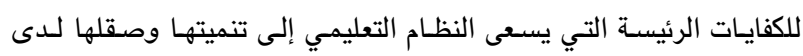

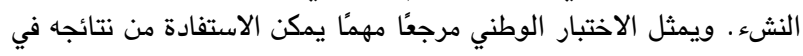

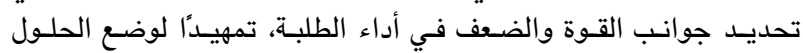

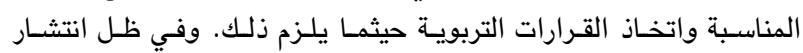

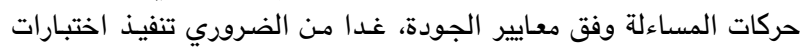

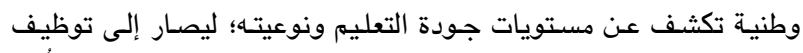

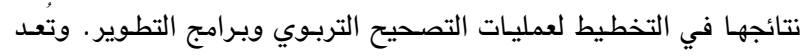

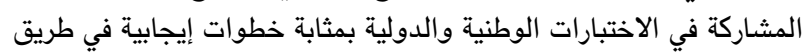

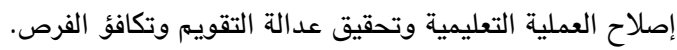

* جامعة اليرموك، الأردن. ( حقوق الطبع محفوظة لجامعة اليرموك، إربد، الأردن. 
عبر مختلف المجموعات الفرعية لمجموعة من المتغيرات. وعندما

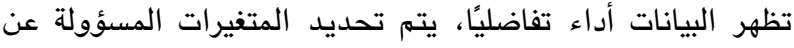

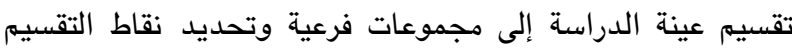

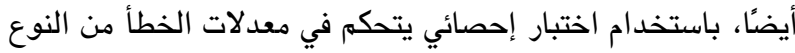

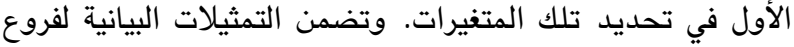

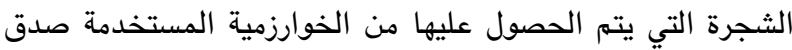

التفسيرات الإحصائية (Zeileis et al., 2008).

وينظر إلى أشجار راش على أنها طريقة شاملة للكثف عن

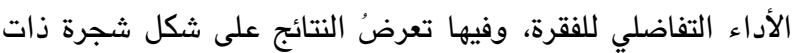

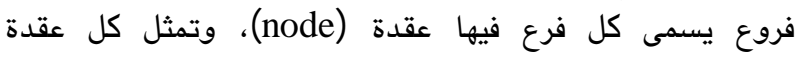

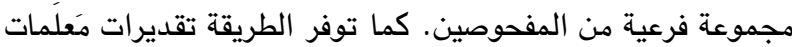

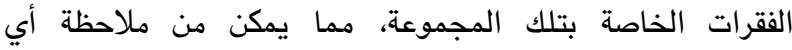

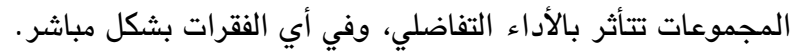

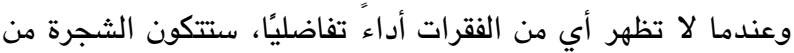

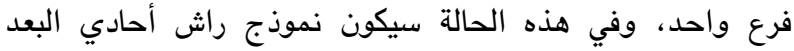

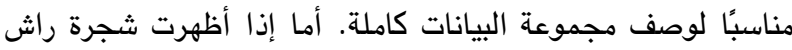

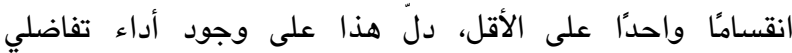

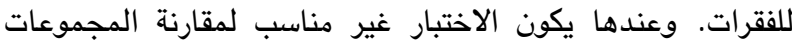

المختلفة من المفحوصين (Strobl et al., 2010).

ويمكن أن تساعد طريقة أشجار راش الباحثين في دراسة

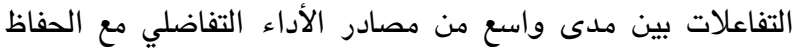

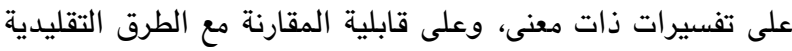

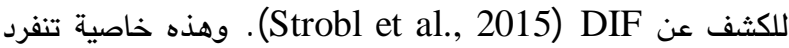
بها هذه الطريقة، وتتميز بها على الطرق الأخرى (Kopf, 2013) .

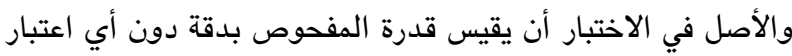

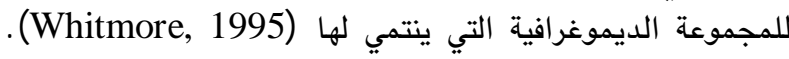
ويتركز الاهتمام في تفسير درجات الاختبار على ثبات القياس عبد الفير

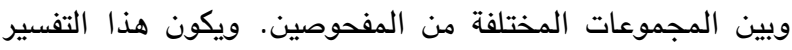

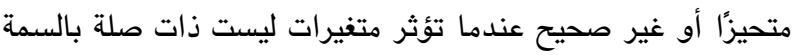

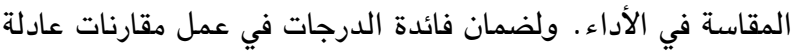

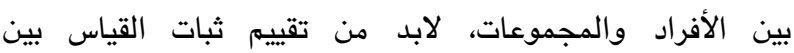
المتقدمين للاختبار عبر المجموعات المختلفة المتعلقة بالجنس

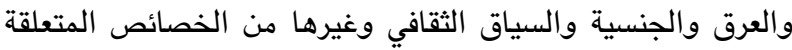

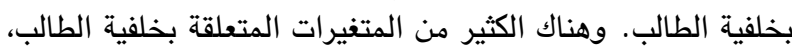

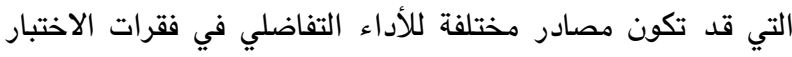
. (Albano \& Rodriguez, 2013)

وتتوكد شيا (Shea, 2013) على أن التحديد الإحصائي

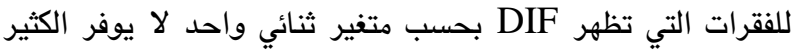

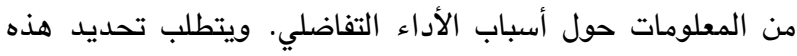
الأسباب مقاربة شاملة لتحليل DIF؛ فخصائص الماتل المفحوصين

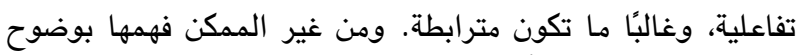

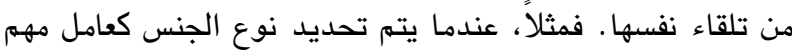
في الأداء التفاضلي، فإنه من المحتمل أن تعمل متغيراء عندات مترابطة

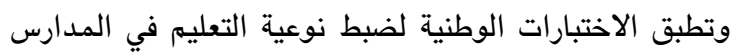

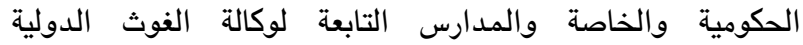

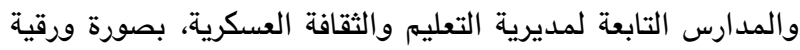

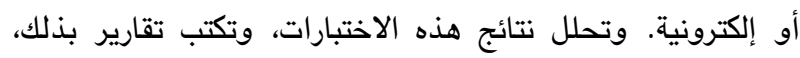
وتقدم للمسؤولين على المستويات كافة لاتخاذ القرارات المناسبة.

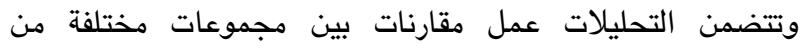
المفحوصين (Jordanian Ministry of Education, 2018). ومن أجل أن تكون هذه القرارات والمقارنات صائبة، يجب أن أن إن إن إن

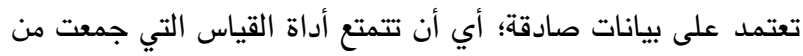

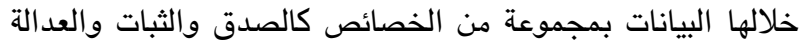

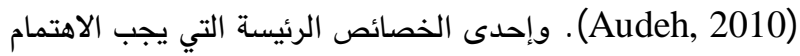
بها في تقييم الاختبارات هي خاصية استقرار القياس ( Stability ) (of Measurement تعرف باسم اللاتغير في القياس (Measurement Invariance)، و يُعرف انتهاك هذه الخاصية على مستوى الفقرة باسم الأداء التفاضلي للفقرة (Differential Item Functioning: DIF) (Komboz et al., 2018) الفقرات غير محقق لمبدأ العدالة بين المفحوصين، مما يهدد صدقه الأنه .(Rover, 2005)

ويقصد بمصطلح الأداء التفاضلي للفقرة (DIF) في الاختبار

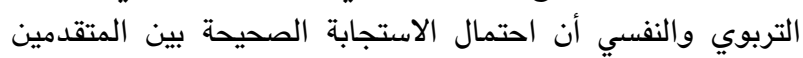

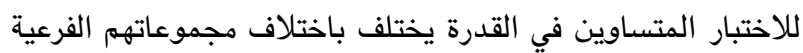

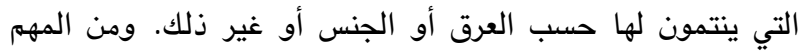

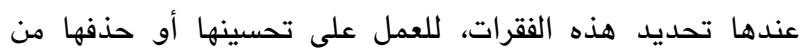
الاختبار (Westers \& Kelderman, 1992).

ويشتمل الأدب التربوي على العديد من الأساليب الإحصائية

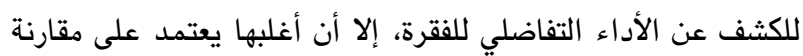

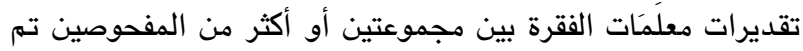

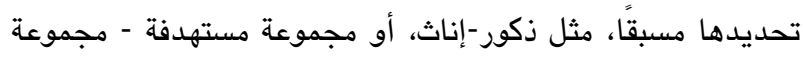

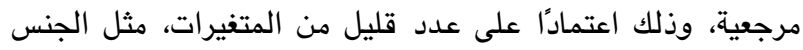

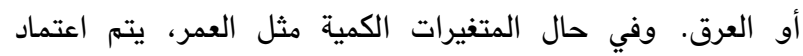

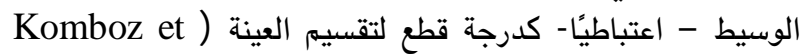
. (al., 2018

واقترح ستروبل وآخرون (Strobl et al., 2010) طريقة

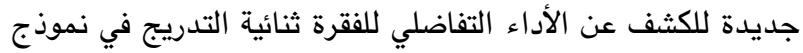

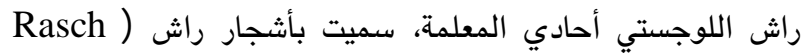
Trees

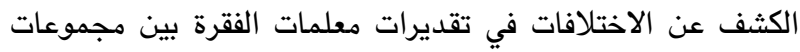

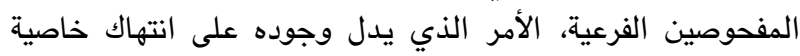

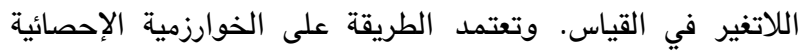

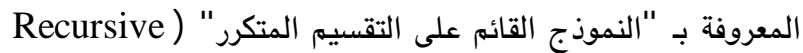

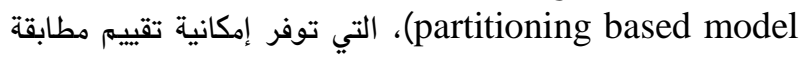

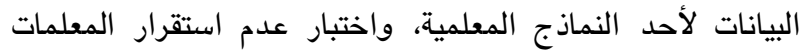


(Change Tests Approach

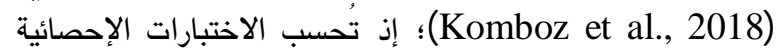

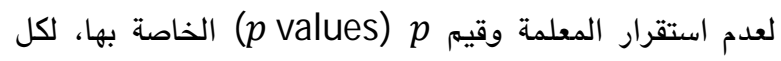

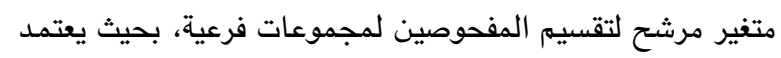

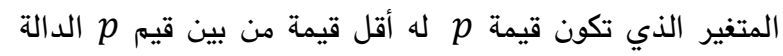

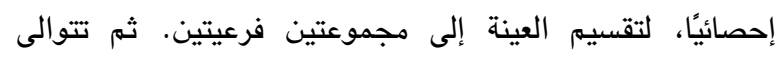

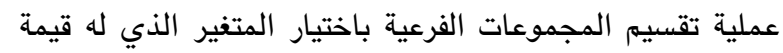

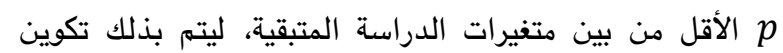

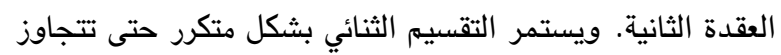

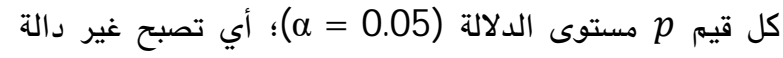

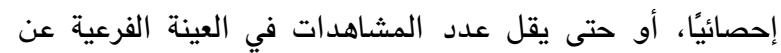
عتبة معينة أقلها (10) (Boehmke \& Greenwell, 2020). ويشير حدوث ذلك إلى استقرار دال إحصائيًا للمعلمة.

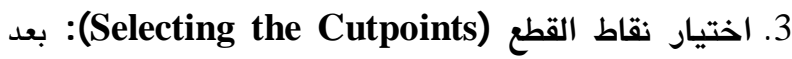
أن يتم اختيار المتفير الذي سيتم تقسيم العينة من خلاله، يته التهم

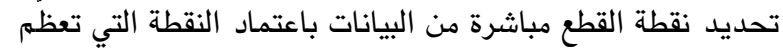

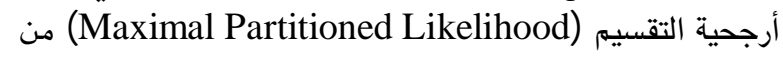
بين جميع نقاط القطع المرشحة ضمن نطاق ذلك المتغير ـ ويرتبط

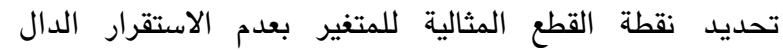

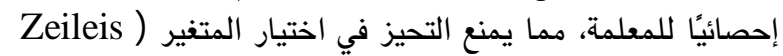
. (et al., 2008

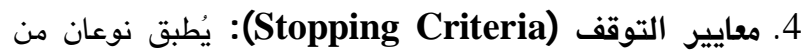
معايير التوقف: الأول هو مستوى الدلالة وعادة ما يتم ضبطه

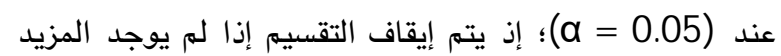

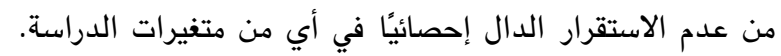

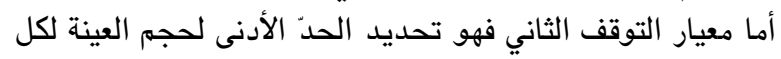

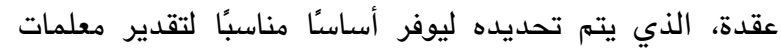

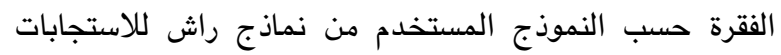

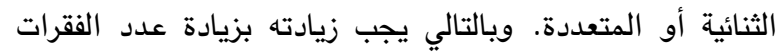

المراد تقدير معالمها (Strobl et al., 2010).

والجدير بالذكر أن هذه الطريقة تعالج مشكلة الاختبار المتكرر

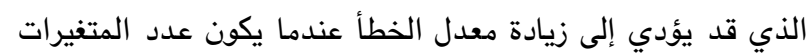

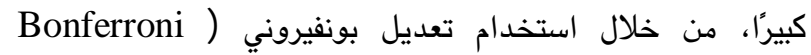
(Adjustment

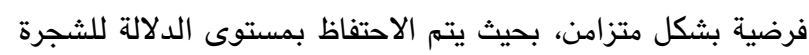

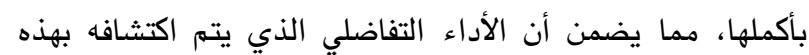

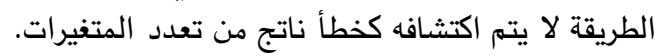
وقد تناولت العديد من الدراسات الأداء التفاضلي للفقرات في دات

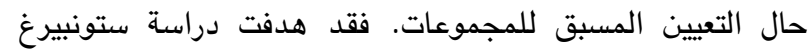
(Stoneberg, 2004) ايداهو (Idaho) في التحصيل في القراءة وفنون اللغة والرياضيات في الراء التفات

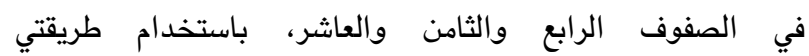

مشتركة أخرى (السكن، والوضع الاقتصادي الاجتماعي، وغيرها)

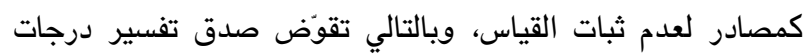

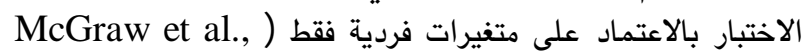

2006 (2006)

ويرى كامبل (Campbell, 1989) أن تناول نوع الجنس

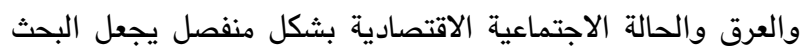

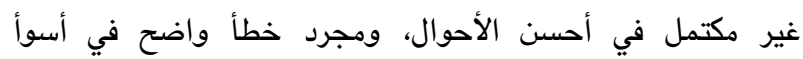

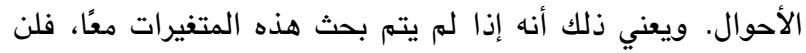

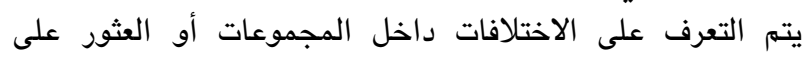

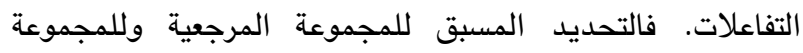

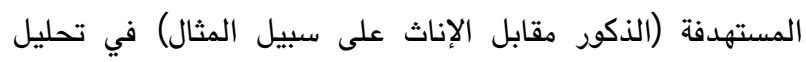

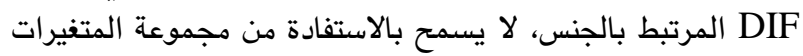

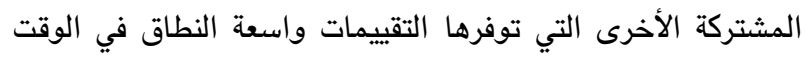

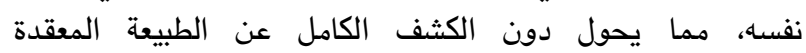
والمترابطة في DIF ) (Zhang, 2001) .

وقد تم تطوير طريقة أشجار راش للتفلب على هذه الته

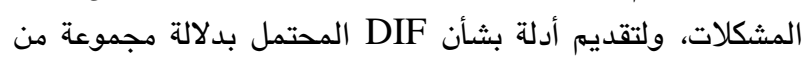

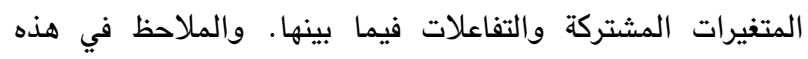

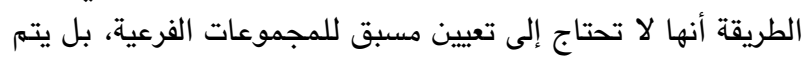

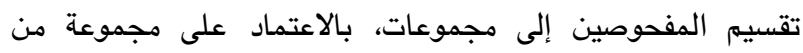

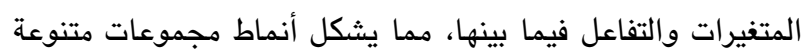

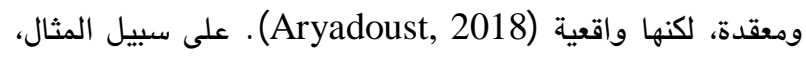

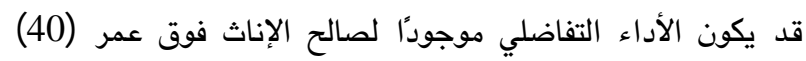

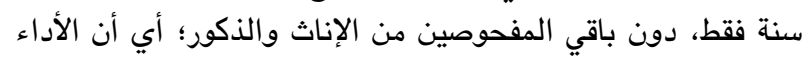

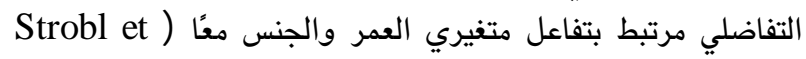

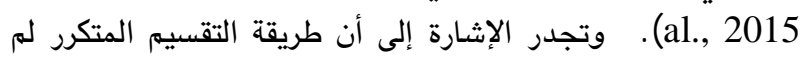

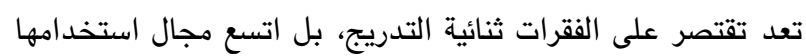

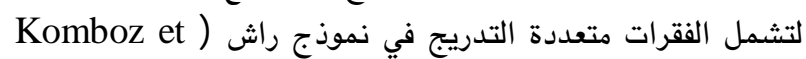
. (al., 2018

ويتم استتاج بنية شجرة راش من البيانات باتباع الخطوات

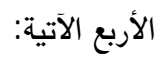

1 Estimating the Item ) تقدير معلمات الفقرة

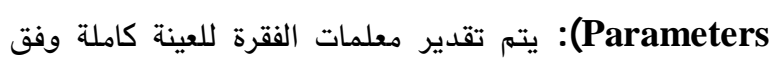

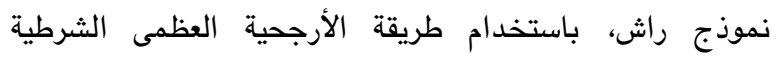
Zeileis et ) (Conditional Maximum Likelihood) .(al. 2008

2. اختبار عدم استقرار المعلمة ( Testing for Parameter

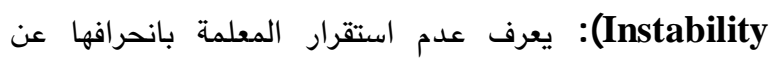

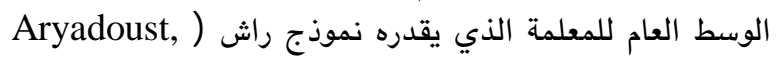

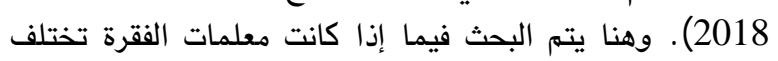

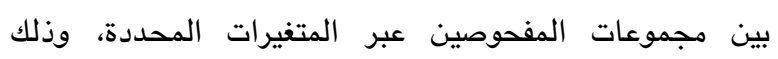
باستخدام منحى "اختبارات التغير البنائي" ( Structural 
(and Kutlu, 2019 إلى الكثف عن الأداء التفاضلي في فقرات الأسئ اختبار مهارات التعلم الأساسية للطلبة الأجانب في جامعة أنقرة، وفق متفيرات الجنس والدولة باستخدام طريقة أشجار راش.

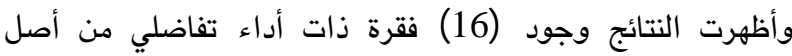

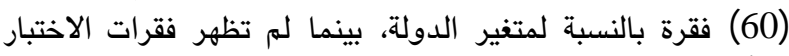
أداء تفاضليًا بالنسبة لمتغير الجنس.

وفيما يتعلق باختبارات الرياضيات الوطنية لضبط نوعية التعليم في الأردن، فقد درس الطراونة (Altarawneh, 2011)

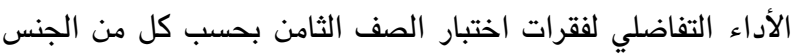

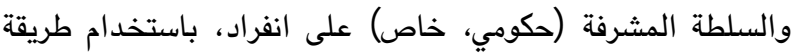

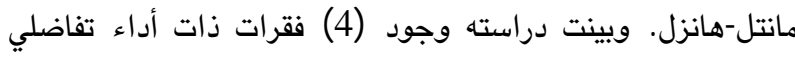

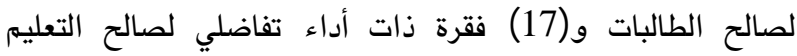

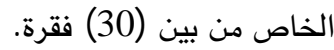

ودرس البرصان (Alpursan, 2013) الأداء التفاضلي

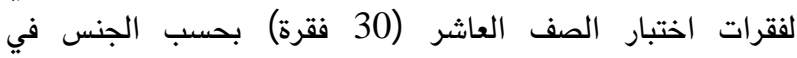

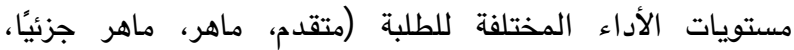

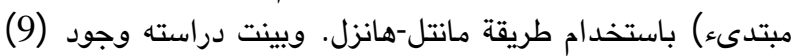

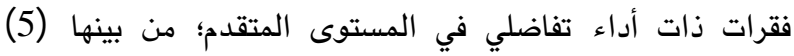

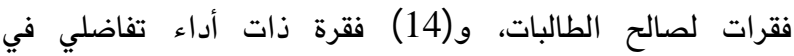

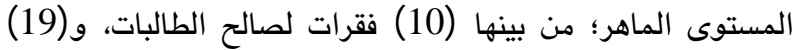

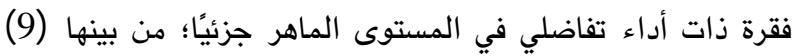

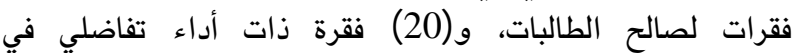

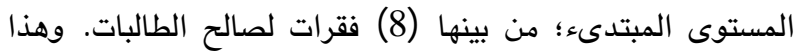

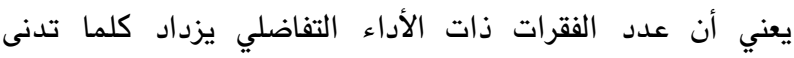

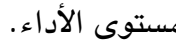

وقد درست فريحات (Frehat, 2014) الأداء التفاضلي

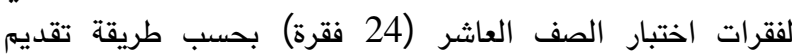

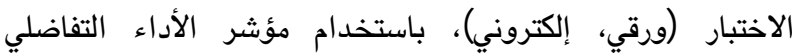

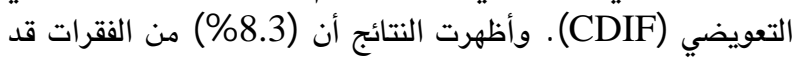

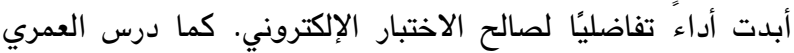

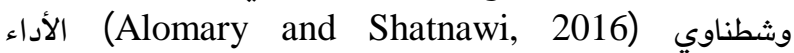
التفاضلي لفقرات اختبار الصف العاشر (24 فقرة) بحسب الجنس (لأنس

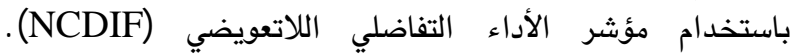

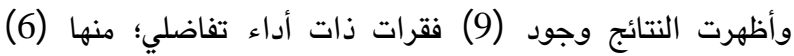
فقرات لصالح الطالبات توزعت على موضوعات الجبر والإلى الحصاء

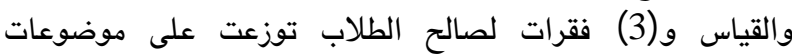
الهندسة والعمليات على الأعداد.

وهكذا تمت دراسة الأداء التفاضلي لاختباري الصفين الثامن

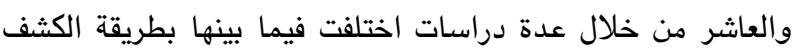

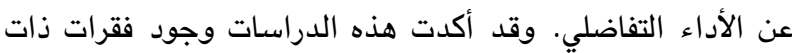

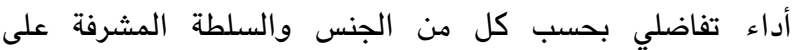
المدارس وطريقة تقديم الاختبار للطلبة بشكل منفصل. وتجدر الجنل
(Simultaneous Item Bias Test :SIBTEST) هانزل (Mantel-Hansel) . وتوفر للدراسة عينات عشوائية تمثل فئل

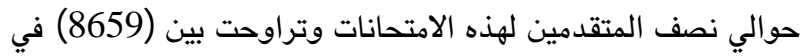

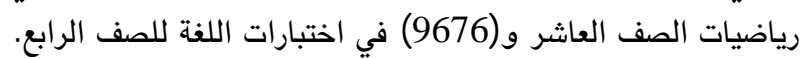

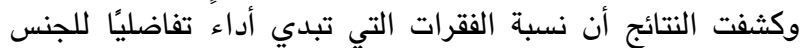

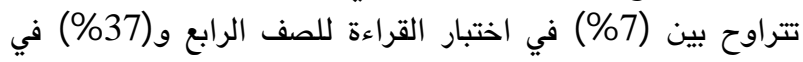

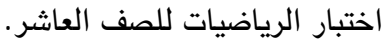

وهدفت دراسة أبو حماد (Abu Hammad, 2008) إلى فئل

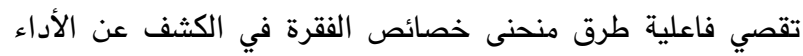
التفاضلي لمتغير الجنس في الاختبار الدولي في الرياضيات. تكون

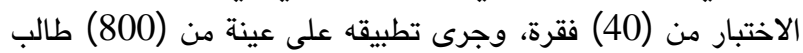

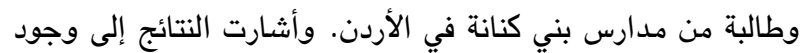

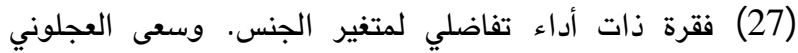

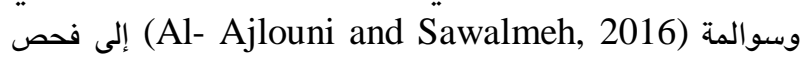
الأداء التفاضلي لفقرات ومموهات اختبار الرياضيات في التقييم

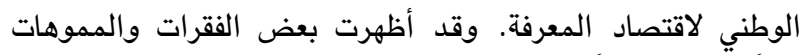

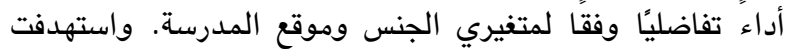
دراسة أبو شندي وكاظم (Abu Shindi and Kazem, 2018) معرفة الأداء التفاضلي لفقرات اختبار الرياضيات في برنامج التنمية

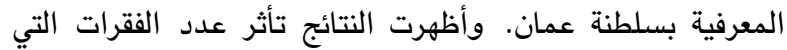
أظهرت أداء تفاضليًا لمتغير الجنس بحجم عينة المفحوصين.

ويوجد عدد قليل من الدراسات التي استخدمت طريقة أشجار

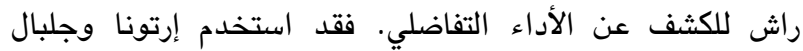
(Ertuna and Gelbal, 2016) الأداء التفاضلي للفقرات في امتحانات تحديد إنجاز الطالب التركية (ÖBBS)

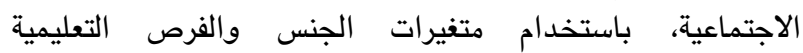

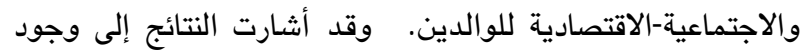

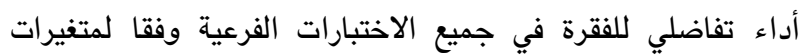
الدراسة. وقارن ليو (Liu, 2017) طريقة أشجار راش بطريقتين

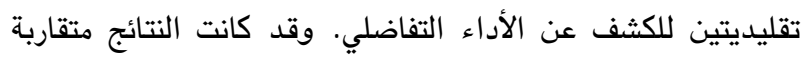

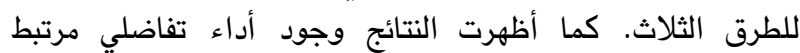
بالخلفية العرقية للطالب فقط، ولم يظهر أداء تفاضلي مرتبط التاء

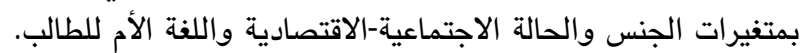

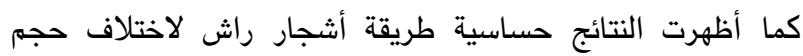

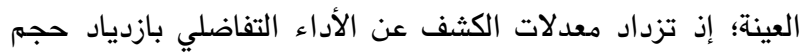

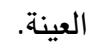

وقد أجرى أريادوست (Aryadoust, 2018) دراسة استخدم فيها طريقة أشجار راش لتحديد أتهديد مصادر الأداء التفاضلي

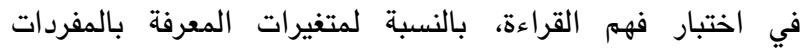

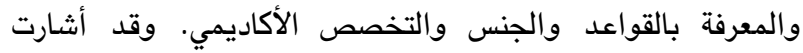

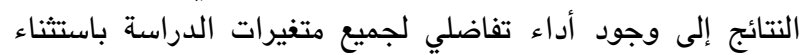

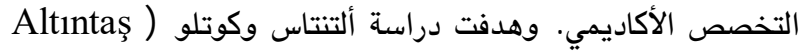




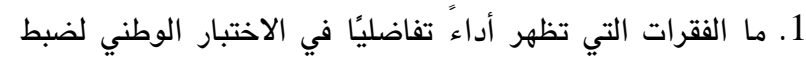

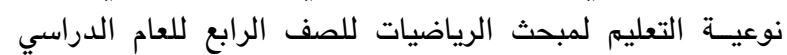

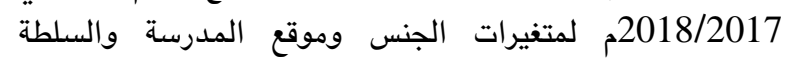
المشرفـة عليه وطريقة تقديم الاختبار، باستخدام طريقة أشجار

راش؟

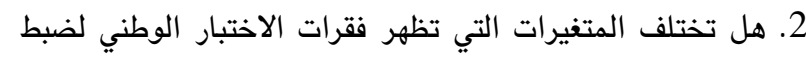

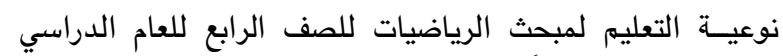

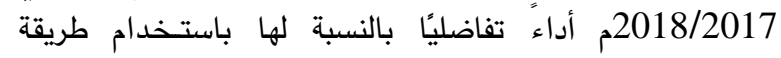
أشجار راش، باختلاف حجم العينة (500،

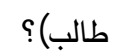

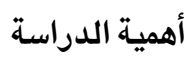

تكتسب الدراسة الحالية أهميتها من أهمية التحقق من خاصية

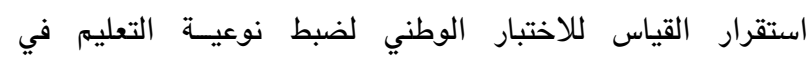

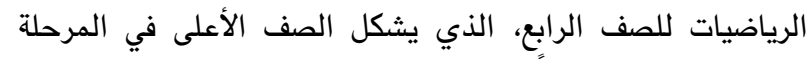

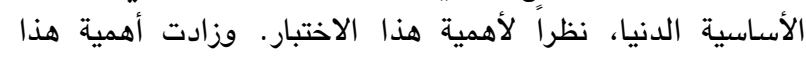

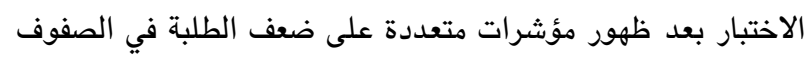

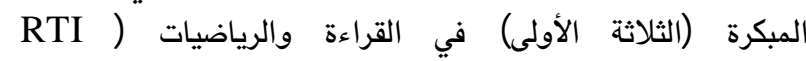

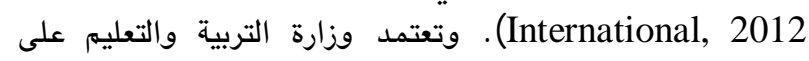

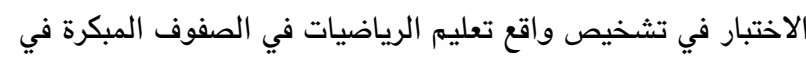

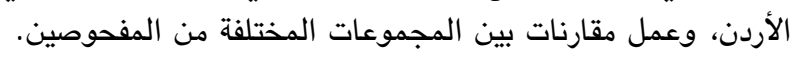
وهذا يستلزم المزيد من الاهتمام بخصائص الاختبات الآنار السيكومترية،

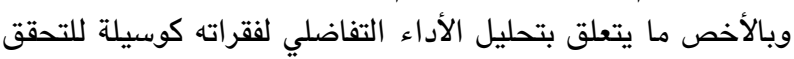

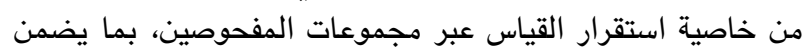

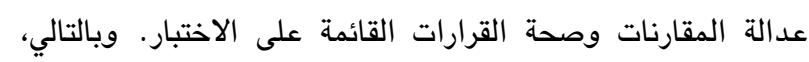

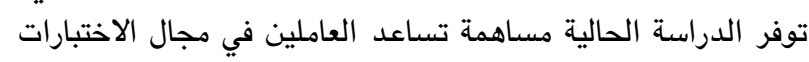

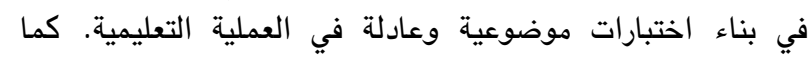

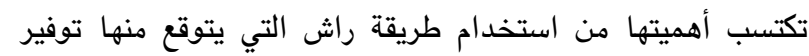

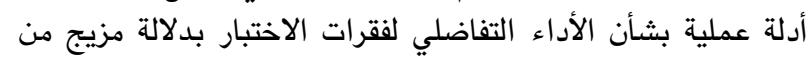

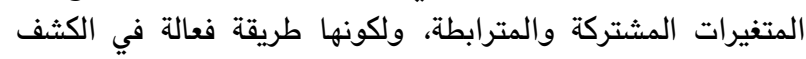

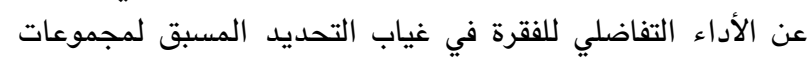

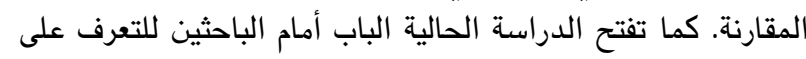

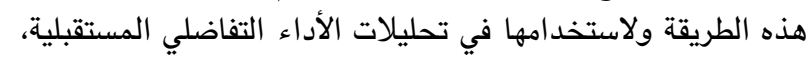
مقارنة بالطرق الأخرى شائعة الاستخدام.

$$
\text { مصطلحات الدراسة }
$$

• أشجار راش: طريقة إحصائية جديدة للكثف عن الأداء

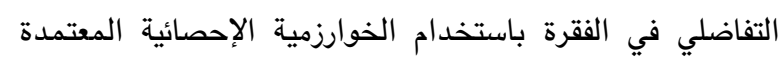

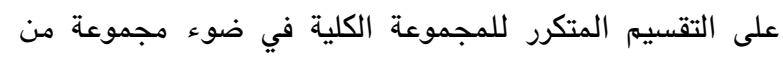
المتغيرات.

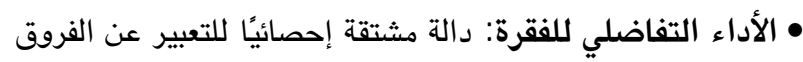

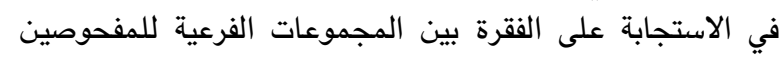
ممن لهم مستوى القدرة نفسها.
الإثارة إلى أن فحص الأداء التفاضلي بحسب متغير واحد أو أكثر

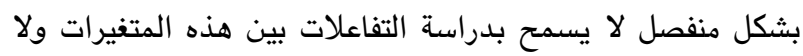

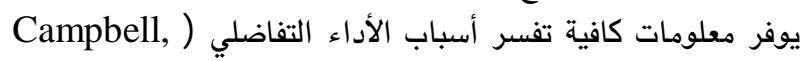

1989).

أما امتحان الصف الرابع، فلم يحظً بأية دراسة حول استقرار

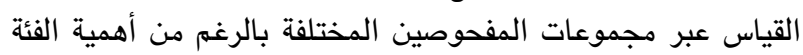

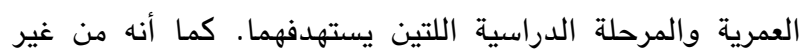

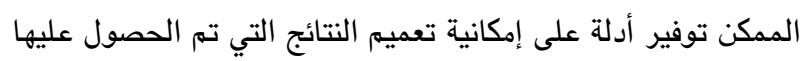

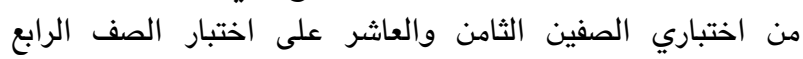

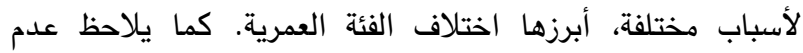

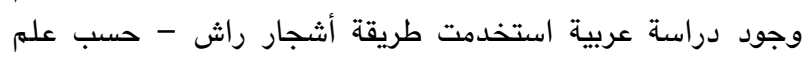

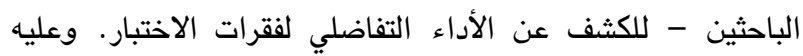

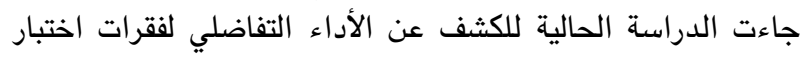

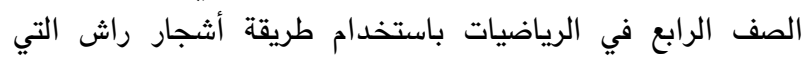

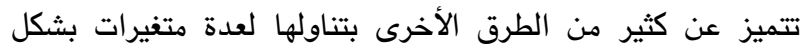
متزامن.

مشكلة الدراسة وسؤالاها

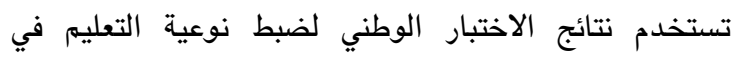
الرياضيات للصف الرابع في مقارنة مستوى الأداء على الإنى الاختبار

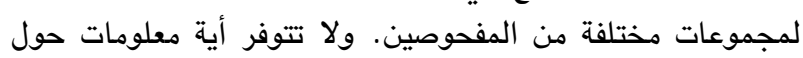
خاصية ثبات القياس لهذا الاختبار بين وعبر تلك الكات المجموعات التهات

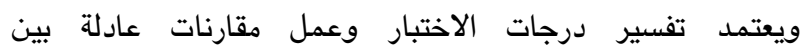

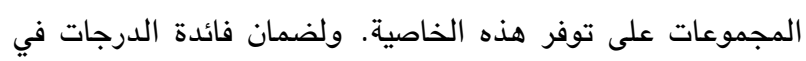

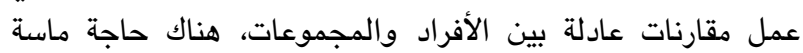

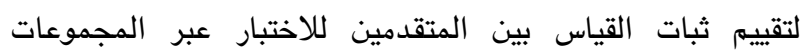

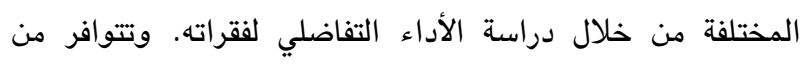

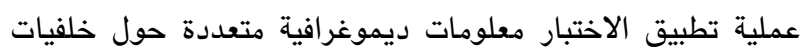

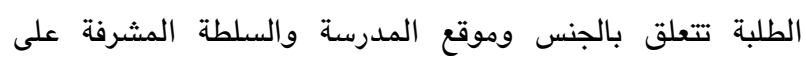

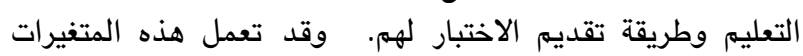

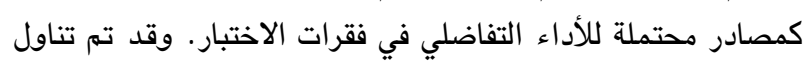

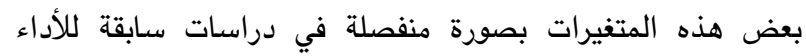

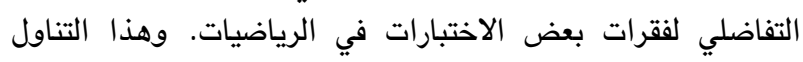

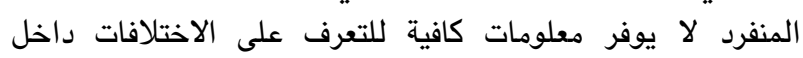

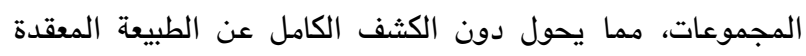

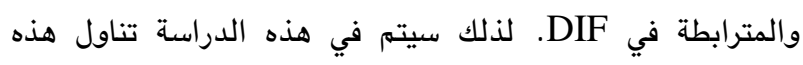

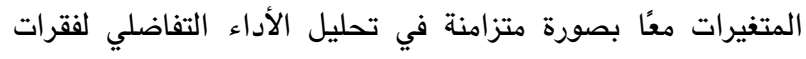

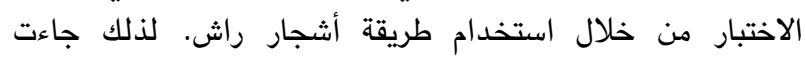

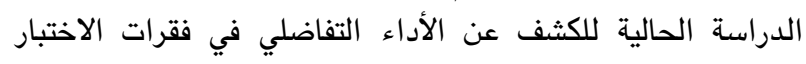

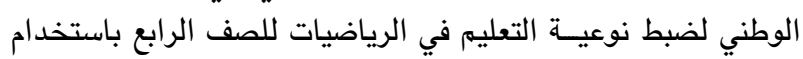

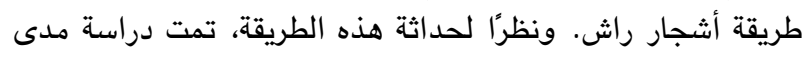
تأثرها بحجم العينة. وبالتحديد، فقد سعت الدراسة للإجابة عن السؤالين الآتيين: 
(Liu)، وأن يكون من ضمنها ما يزيد على (600) لأغراض الحصول على تقديرات مستقرة لمعلمة الصعوبة.

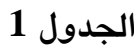

توزيع العينة حسب الجنس وموقع المدرسة والسلطة المشرفة وطريقة تقديم الاختبار

\begin{tabular}{|c|c|c|c|}
\hline النسبة المئوية & عدد الطلبة & المتغير & المتغير \\
\hline$\% 46.7$ & 701 & ذكور & \multirow{2}{*}{ الجنس } \\
\hline$\% 53.3$ & 799 & إناث & \\
\hline$\% 73.5$ & 1103 & مدينة & \multirow{2}{*}{ المنطقة } \\
\hline$\% 26.5$ & 397 & قرية & \\
\hline$\% 79.2$ & 1188 & الحكومة & \multirow{3}{*}{ السلطة المشرفة } \\
\hline$\% 12.9$ & 193 & وكالة الغوث & \\
\hline$\% 7.9$ & 119 & الخاصة & \\
\hline$\% 91.4$ & 1371 & ورقي & طريقة تقديم \\
\hline$\% 8.6$ & 129 & إلكتروني & الاختبار \\
\hline$\% 100$ & 1500 & & المجموع \\
\hline
\end{tabular}

الأداة الرئيسة المستهدفة هي الاختبار الوطني لضبط نوعية

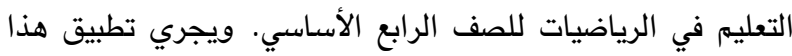

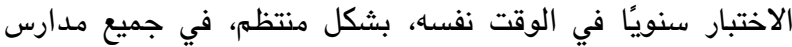

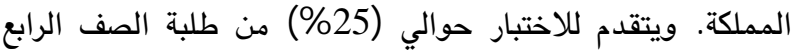

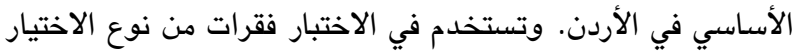

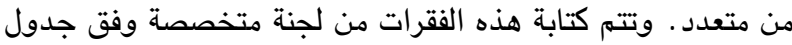
مواصفات وقواعد محددة، وتتم مراجعة الفقرات من لجنة أخرى.

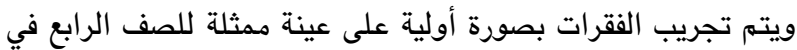

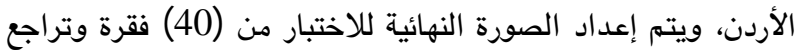
من فريق من المتخصصين. وتضمن هذه المراجعات الصدق الصات

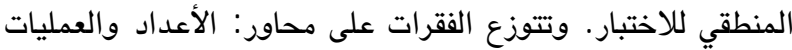

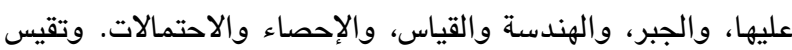

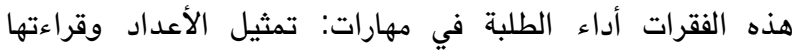

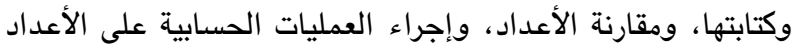

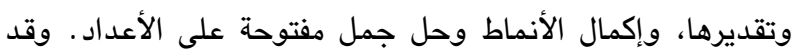

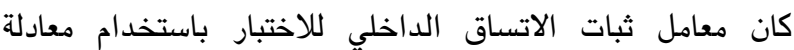
"كرونباخ ألفا" (0.91) للصورة الورقية و و(0.89) للصورة

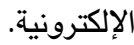
إجراءات الدراسة

تم الحصول على ملف إكسل بالبيانات اللازمة من إدارتي الامتحانات والاختبارات ومركز الملكة رانيا العبد الله لتكنولوجيا التعليم والمعلومات في وزارة التربية والتعليم. وقد تمت التانيد تنقية
• الاختبار الوطني لضبط نوعية التعليم: اختبار سنوي تعدّه

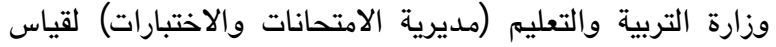

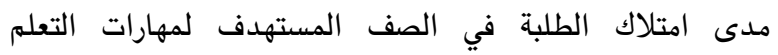
الأساسية ومستويات أداء الطلبة في المباحث التي اختبروا فيها.

$$
\text { محددات الدراسة }
$$

اقتصرت الدراسة الحالية على طلبة الصف الرابع الأساسي

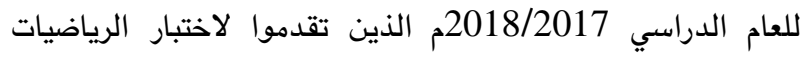

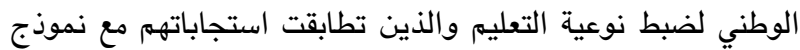

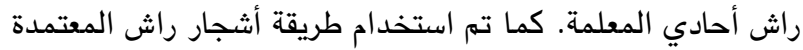

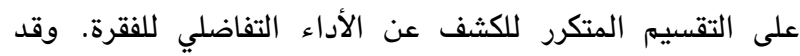

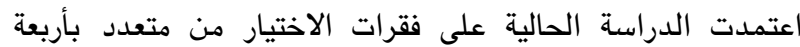

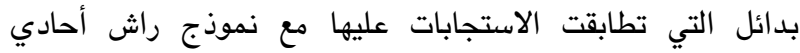

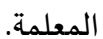

الطريقة

منهج الدراسة

تم استخدام المنهج الوصفي التحليلي للكثف عن الفقرات التي

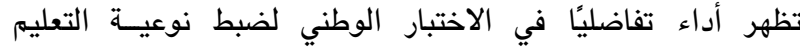

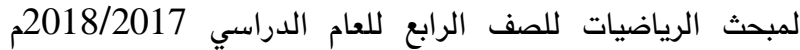

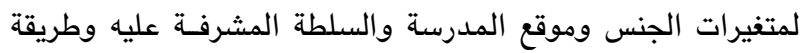

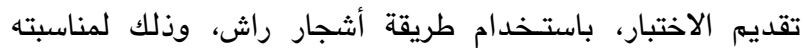

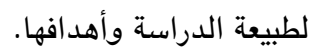

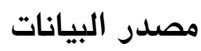

المصدر الرئيسي لبيانات الدراسة هو ملف استجابات طلبة

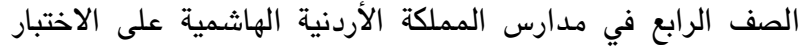

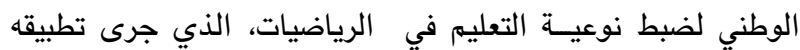

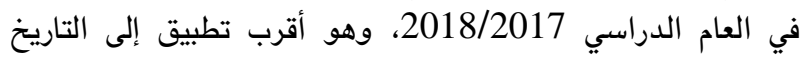

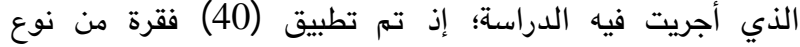

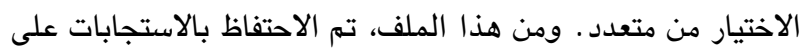

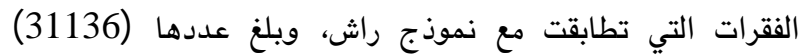
استجابة على (25) فقرة. وشكلت هذه الاستجابات ملف بيات فيانات

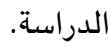

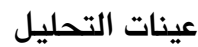
تكونت عينة التحليل الأولى لغرض الإجابة عن السؤال الأول

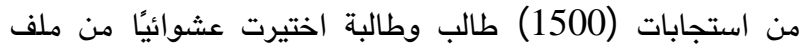

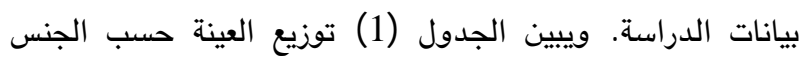

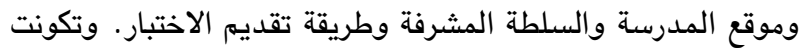

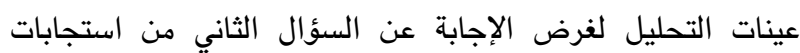

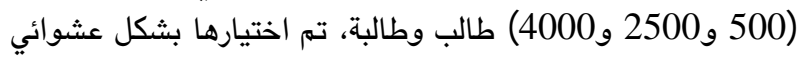
من ملف بيانات الدراسة. والاعتبار الذي روعي في هذه الأعداد هو

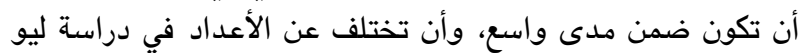


كافية للطلبة ليجيبوا عن جميع الفقرات. كما تم التحقق من افتراض الفران

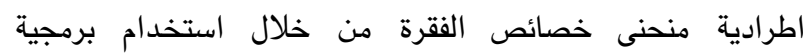
(BILOG-MG 3)

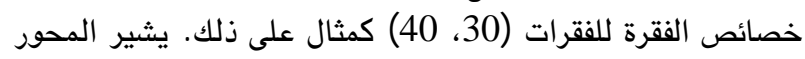

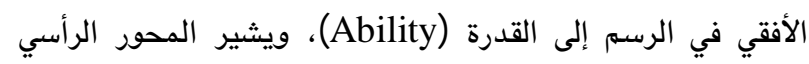
إلى احتمال (Probability) إجابة الفقرة إجابة صحيحة.

وقد تم تحليل البيانات باستخدام برمجية ( BILOG-MG 3)، للتحقق من مطابقة الأفراد لنموذج راش، باست باستخدام الإحصائي

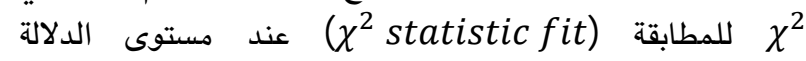
وة مرت إجراءات التدليل على مطابقة البيانات للنموذج المستخدم.

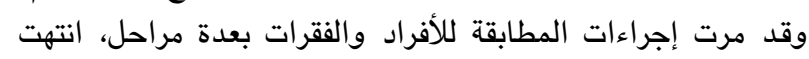

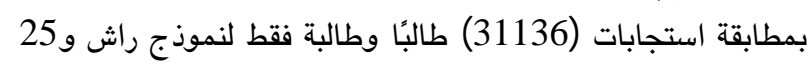
فقرة من فقرات الاختبار، وهذه الاستجابات شكلت ملف بلف بيانات الدراسة الذي منه اختيرت عينات التحليل. نتائج الدراسة ومناقشتها

يبين الجدول (2) الإحصاءات الوصفية لأداء الطلبة في

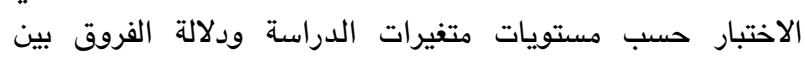

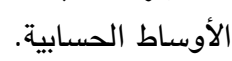

الييانات وحذف المتغيرات والبيانات التي ليست لها علاقة بالدراسة، ثم تحويل الملف إلى ملف (SPSS) .

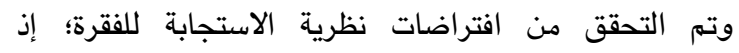

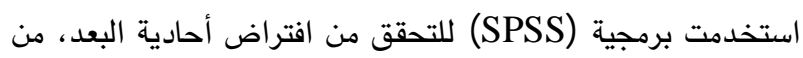

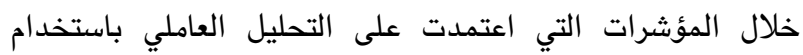

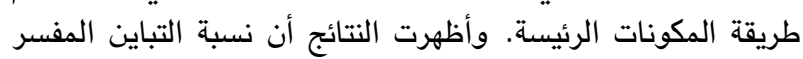

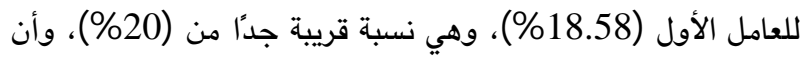

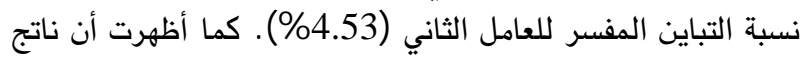

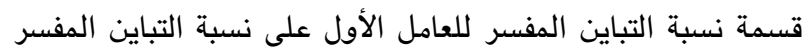

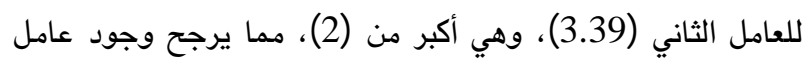

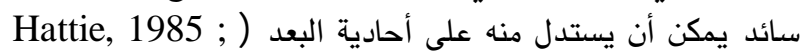

.(Reckase, 1997

واستخدمت الحزمة الإحصائية (Subscore Package)

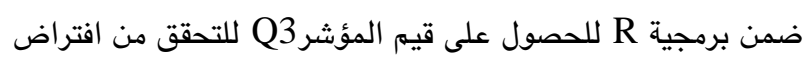

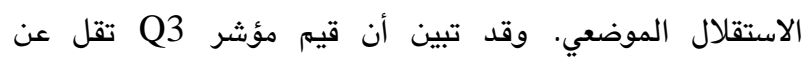

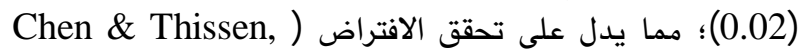

وهناك مؤشرات على تحقق افتراض التحرر من السرعة لكون

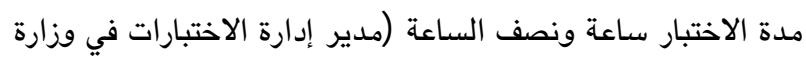

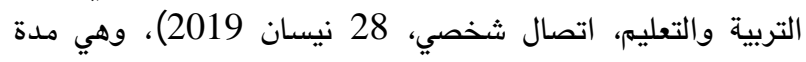

الشكل 1

\section{منحنيات خصائص الفقرة للفقرات (30، 40)}

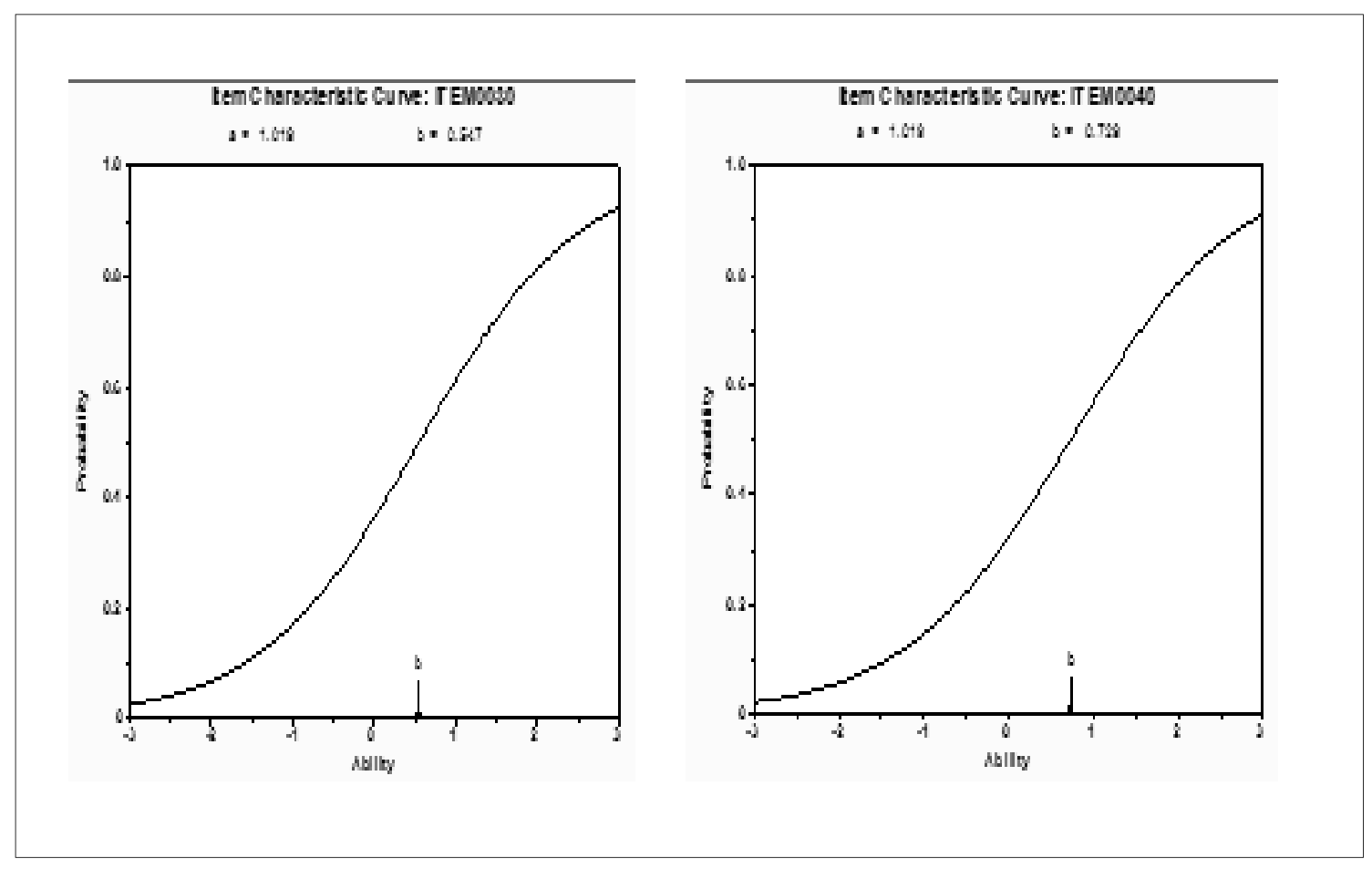




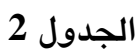

الإحصاءات الوصفية لأداء الطلبة في الاختبار حسب مستويات متغيرات الدراسة ودلالة الفروق بين الأوساط الحسابية

\begin{tabular}{|c|c|c|c|c|c|c|}
\hline الإحصائية & قيمة الاختبار & المعياري & الحسبابي & 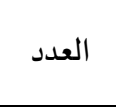 & فئات المتغير & المتغير \\
\hline \multirow{2}{*}{0.001} & \multirow{2}{*}{$\mathrm{t}=-3.47$} & 7.926 & 24.26 & 14426 & ذكور & \multirow{2}{*}{ الجنس } \\
\hline & & 7.667 & 24.57 & 16710 & إناث & \\
\hline \multirow{2}{*}{0.336} & \multirow{2}{*}{$\mathrm{t}=-3.47$} & 7.712 & 24.46 & 22348 & مدينة & \multirow{2}{*}{ موقع المدرسة } \\
\hline & & 7.983 & 24.36 & 8788 & قرية & \\
\hline \multirow{3}{*}{0.000} & \multirow{3}{*}{$\mathrm{F}=661.57$} & 7.678 & 23.61 & 24483 & الحكومة & \multirow{3}{*}{ السلطة المشرفة } \\
\hline & & 7.105 & 27.65 & 4123 & الخاصة & \\
\hline & & 7.978 & 27.09 & 2530 & وكالة الفوث & \\
\hline \multirow{2}{*}{0.000} & \multirow{2}{*}{$\mathrm{t}=-12.45$} & 7.828 & 24.26 & 28329 & ورقي & \multirow{2}{*}{ طريقة تقديم الامتحان } \\
\hline & & 7.164 & 26.17 & 2807 & إلكتروني & \\
\hline
\end{tabular}

المدرسة والسلطة المشرفـة وطريقة تقديم الاختبار، باستخدام

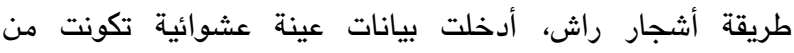

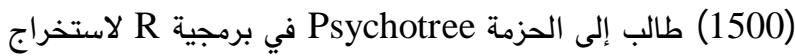

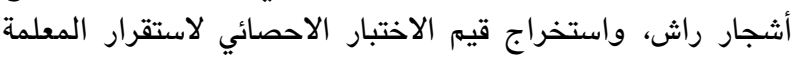

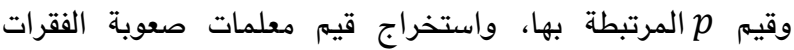
للمجموعات الفرعية. وييين الشكل (2) شجرة راش واش بالنسبة

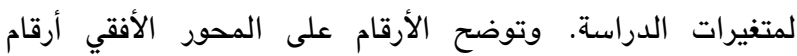

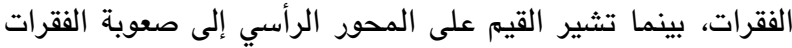
مقدرة بحسب نظرية الاستجابة للفقرة.

تظهر النتائج في الجدول (2) وجود فروق ذات دلالة إحصائية

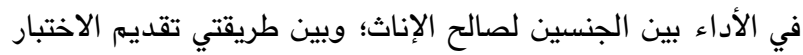

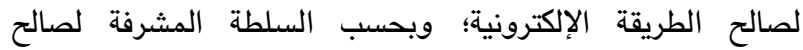

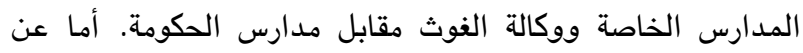

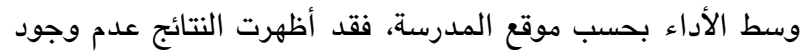

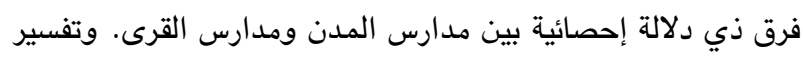

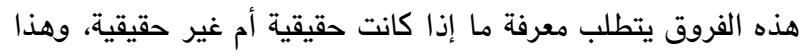

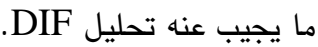
للإجابة عن السؤال الأول المتعلق بالكثف عن الفقرات التي

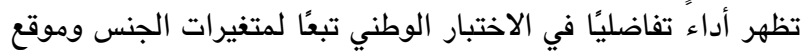

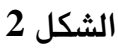

شجرة راش للكثف عن الأداء التفاضلي للفقرات بالنسبة لمتغيرات الدراسة

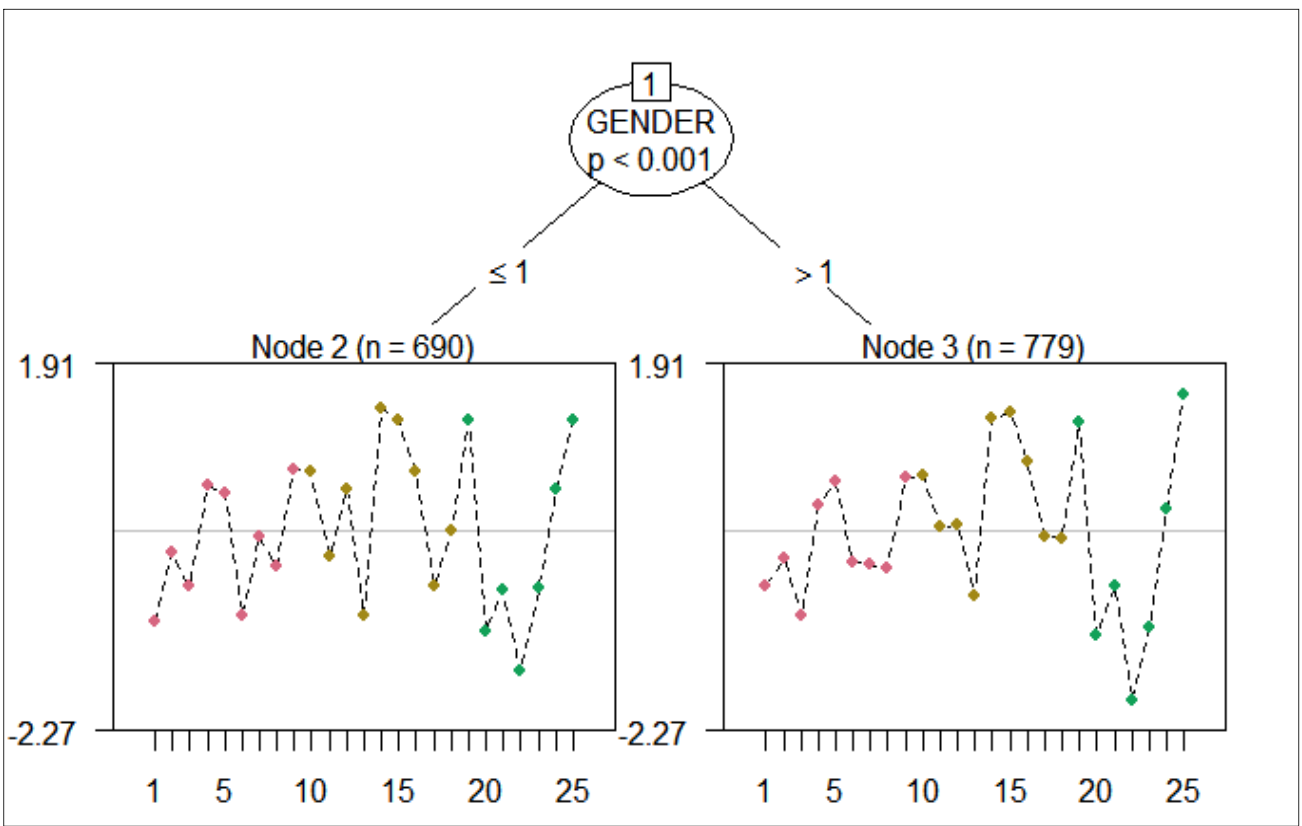


بمعنى أن هذه الفقرات مرشحة لان تبدي أداء تفاضليًا لمتفير

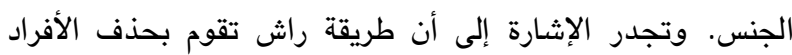

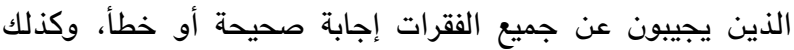

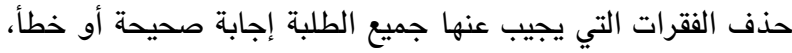

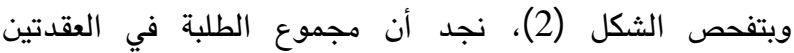

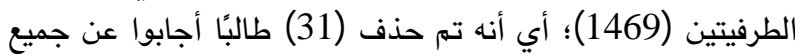

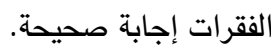

ويبين الجدول (3) قيم الاختبار الإحصائي لاستقرار المعلمة

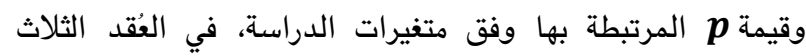
لشجرة راش.
يُظهر الشكل (2) أن الثجرة تتضمن ثلاث عُقد؛ وفيها يقسم

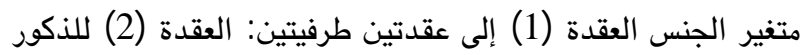

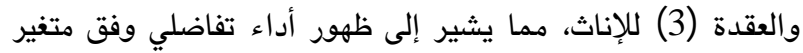

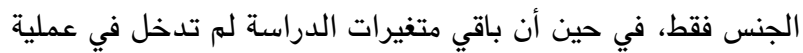

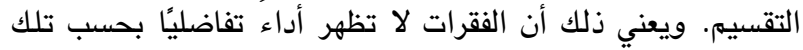

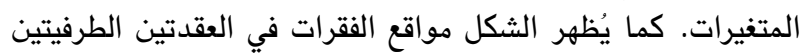

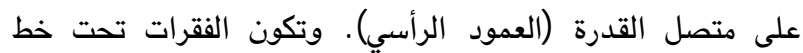

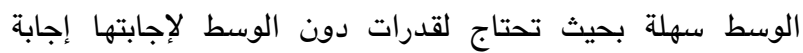

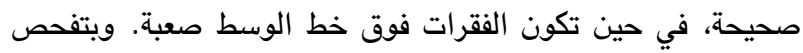
الشكل (2) بدقة يتبين وجود اختلاف ظاهري بين أبعاد الفقرات

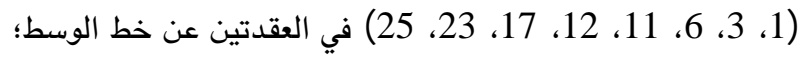

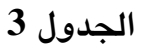

قيم الاختبار الإحصائي لاستقرار المعلمة وقيمة p المرتبطة بها لمتغيرات الدراسة

\begin{tabular}{|c|c|c|c|c|c|}
\hline طريقة تقديم الاختبار & السلطة & المنطقة & الجنس & لعقدة & \\
\hline 47.714 & 28.54 & 37.8 & 114.75 & الاختبار الإحصائي & \multirow{2}{*}{ العقدة 1} \\
\hline 0.251 & 0.99 & 0.89 & $* *<0.004 e^{-5}$ & قيمة & \\
\hline 33.68 & 30.25 & 32.90 & - & الاختبار الإحصائي & \multirow{2}{*}{ العقدة 2} \\
\hline 0.97 & 0.998 & 0.98 & - & قيمة p & \\
\hline 45.23 & 34.71 & 37.18 & - & الاختبار الإحصائي & \multirow{2}{*}{ العقدة 3} \\
\hline 0.32 & 0.95 & 0.85 & - & قيمة p & \\
\hline
\end{tabular}

** قيمة p المرتبطة بالمتغير الذي تم اختياره للتقسيم.

للاستقلال بدرجات حرية (1). ويعد الاختلاف بين التوزيعين

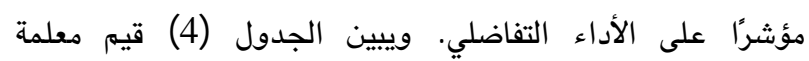

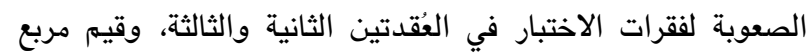

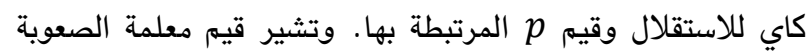

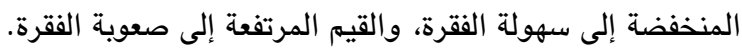

يلاحظ من الجدول (3) أن متغير الجنس هو المتغير الوحيد

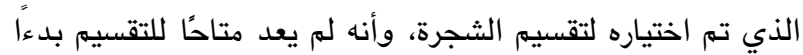

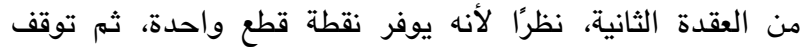

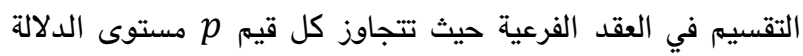
( ) $0.05=0$ ) مما يثير إلى وجود استقرار في المعلمة. ونظرا لأن طريقة أشجار راش لا توفر اختبارًا إحصائيًا للأداء

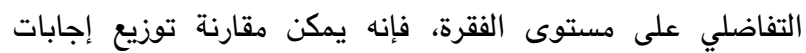
الذكور مع توزيع إجابات الإناث باستخدام اختبار مربع كائ بـائ

الجدول 4 قيم معلمة الصعوية لفقرات الاختبار في العقدتين الثانية والثالثة وقيم مربع كاي للاستقلال وقيم p المرتبطة بها

\begin{tabular}{|c|c|c|c|c|}
\hline قيمة p & اختبار مربع كاي & معلمة الصعوبة في العقدة & هعلمة الصعوبة في العقدة & الفقرة \\
\hline 0.003 & 9.05 & -0.626 & -1.019 & فقرة 1 \\
\hline 0.75 & 0.10 & -0.310 & -0.230 & فقرة 2 \\
\hline 0.03 & 4.71 & -0.969 & -0.631 & فقرة 3 \\
\hline 0.20 & 1.66 & 0.309 & 0.522 & فقرة 4 \\
\hline 0.16 & 1.94 & 0.571 & 0.435 & فقرة 5 \\
\hline
\end{tabular}




\begin{tabular}{|c|c|c|c|c|}
\hline قيمة p & اختبار مربع كاي & معلمة الصعوبة في العقدة & معلمة الصعوبة في العقدة & الفقرة \\
\hline 0.00 & 21.8 & -0.345 & -0.960 & فقرة 6 \\
\hline 0.05 & 3.83 & -0.366 & -0.069 & فقرة 7 \\
\hline 0.94 & 0.01 & -0.422 & -0.397 & فقرة 8 \\
\hline 0.76 & 0.1 & 0.609 & 0.698 & فقرة 9 \\
\hline 0.92 & 0.01 & 0.641 & 0.676 & فقرة 10 \\
\hline 0.01 & 7.73 & 0.051 & -0.277 & فقرة 11 \\
\hline 0.01 & 7.25 & 0.083 & 0.478 & فقرة 12 \\
\hline 0.07 & 3.4 & -0.741 & -0.970 & فقرة 13 \\
\hline 0.68 & 0.18 & 1.284 & 1.401 & فقرة 14 \\
\hline 0.31 & 1.04 & 1.354 & 1.274 & فقرة 15 \\
\hline 0.24 & 1.39 & 0.789 & 0.683 & فقرة 16 \\
\hline 0.00 & 19.34 & -0.067 & -0.622 & فقرة 17 \\
\hline 0.76 & 0.09 & -0.080 & -0.001 & فقرة 18 \\
\hline 0.88 & 0.02 & 1.236 & 1.274 & فقرة 19 \\
\hline 0.89 & 0.02 & -1.182 & -1.132 & فقرة 20 \\
\hline 0.60 & 0.28 & -0.619 & -0.657 & فقرة 21 \\
\hline 0.07 & 3.33 & -1.925 & -1.580 & فقرة 22 \\
\hline 0.00 & 8.34 & -1.091 & -0.648 & فقرة 23 \\
\hline 0.16 & 1.96 & 0.251 & 0.478 & فقرة 24 \\
\hline 0.01 & 6.46 & 1.565 & 1.274 & فقرة 25 \\
\hline
\end{tabular}

المواد العلمية والرياضيات لدى الذكور أكثر منها لدى الإناث، ومن المعلوم أن إتقان المهارات يرتبط بتقدير الذات الذكر الثر منات لثقة بالنفس.

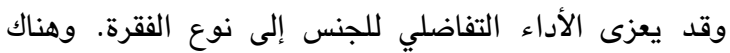
دراسات تؤكد أن أداء الذكور أفضل من أداء الإناث في فقراء الترات

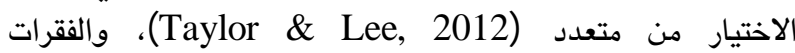

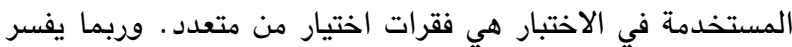

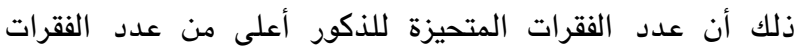

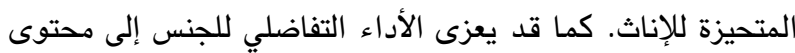

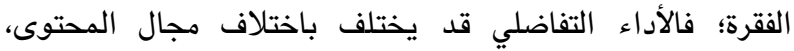

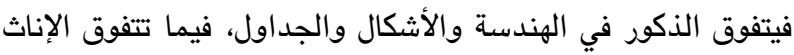
في الجبر (Garner \& Engelhard, 1999).

كما قد يعزى الأداء التفاضلي للجنس إلى أن الفقرات التي إني

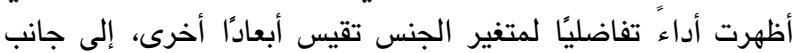

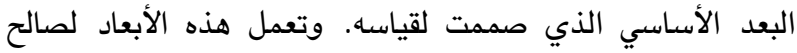
طرف على حساب الطرف الآخر . فقد تتصل هذه الأبعاد باستخدام
يؤكد الجدول (4) أن الفقرات (1، 3، 6، 11، 12، 17،

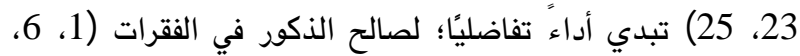

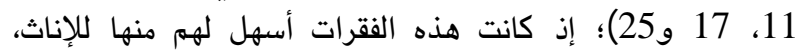

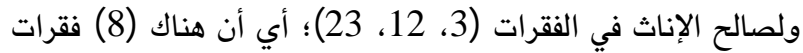

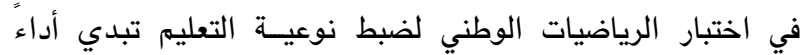
تفاضليًا لمتفير الجنس حسب طريقة أشجار راش، من أصل (25)

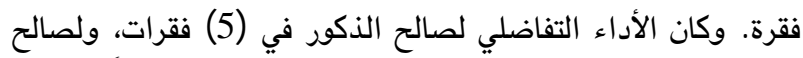

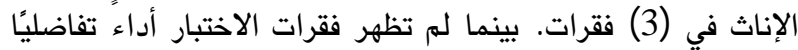

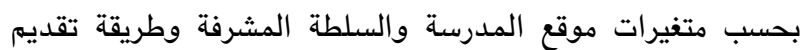

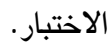

وقد يكون الاختلاف في الأداء بين الذكور والإناث على

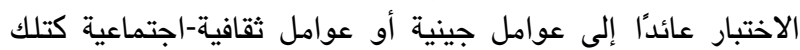

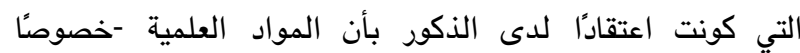

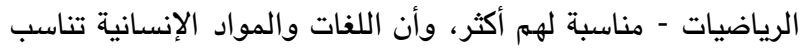

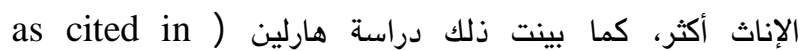

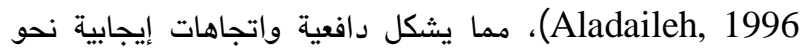


يتناقض مع الدراسات التي تمت لامتحاني الصفين الثامن والعاشر.

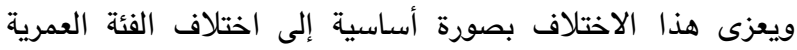

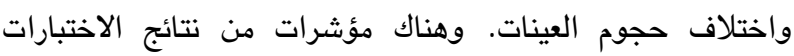

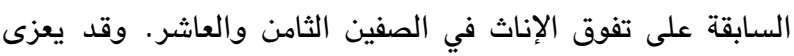

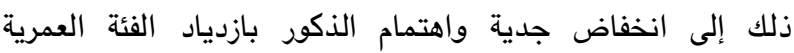

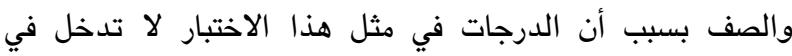

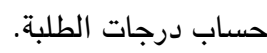

وتتفق نتائج الدراسة الحالية مع نتائج دراسة ستونبيرج (Stoneberg, 2004)

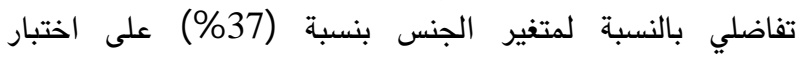

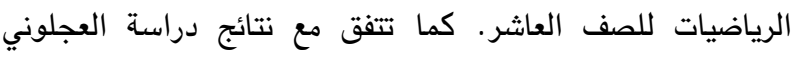
وسوالمة (Al-Ajlouni and Sawalmeh, 2016) التياض في أظهرت

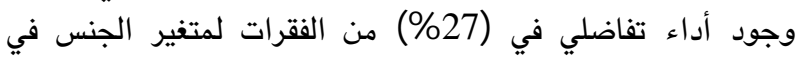

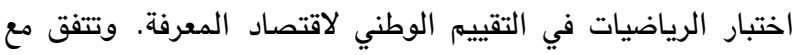

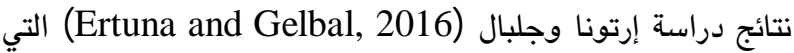

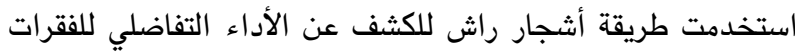

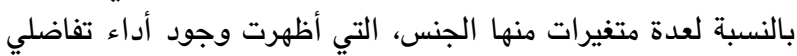

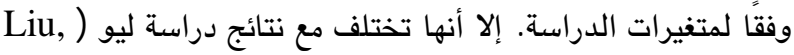

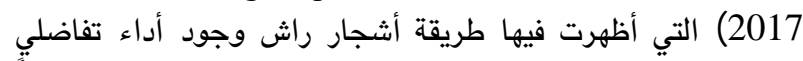

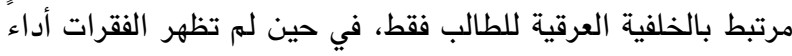

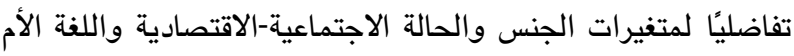

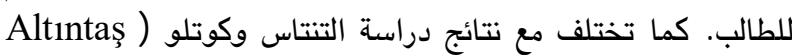
(and Kutlu, 2019

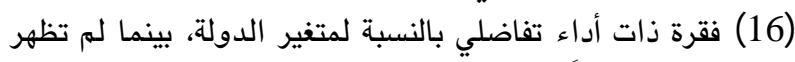
فقرات الاختبار أداء تفاضليًا بالنسبة لمتغير الجنس.

وللإجابة عن السؤال الثاني المتعلق بتحديد المتفيرات التي

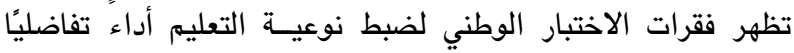

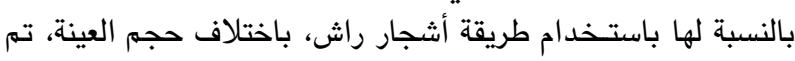

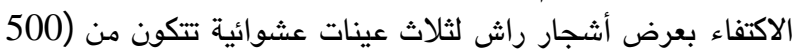

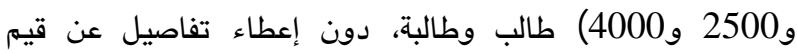

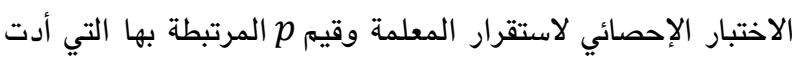

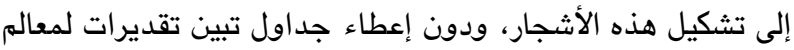
الصعوبة للفقرات في المجموعات المختلفة. وفيما يلي عرض الإن لنتائج

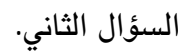

\section{العينة الأولى: (500) طالب وطالبة}

يبين الثكل (3) شجرة راش للكثف عن الأداء التفاضلي

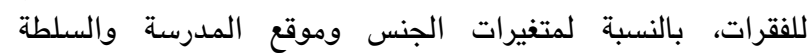
المشرفة وطريقة تقديم الاختبار، للعينة الأولى (500 طالب البهرية وطالبة) .
القوانين أو عملية عقلية أو غموض ما أو خلل في صياغة الفقرة. ومن الملاحظ من النتائج أن أداء الذكور كان أنس أفضل على على الفي الفقرات

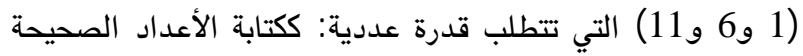

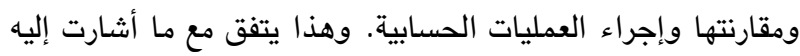
أبو حماد (Abu Hammad, 2008) من تفوق الذكور في القدرة

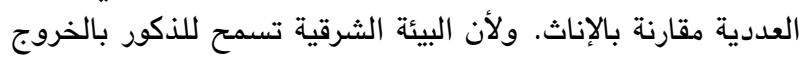

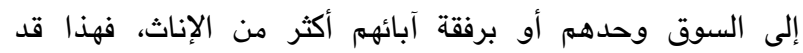

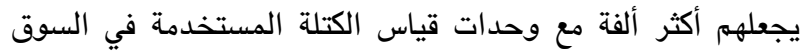

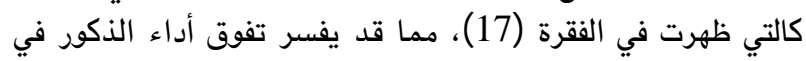
هذه الفقرة. - مالتي فهرت

وأظهر تفحص المسائل التي تقيس مهارة تحديد فرص حدوث القراث

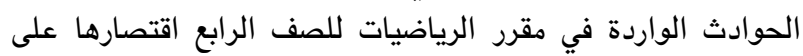

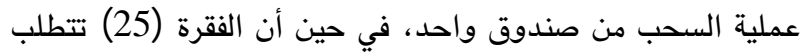

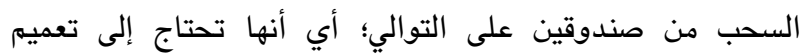

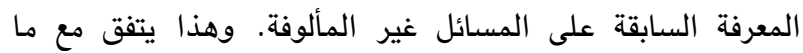

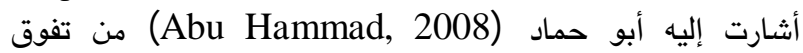
الذكور في ذلك، بينما تفضل الإناث الاستخدام الروتيني للقوانين،

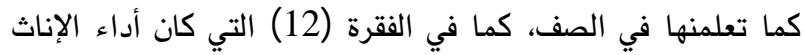

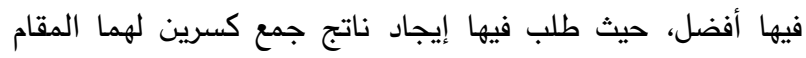

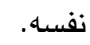

وتتطلب الإجابة عن الفقرة (3) قدرة لغوية إلى جانب القدرة

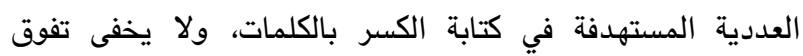
الإناث على الذكور في القدرة اللفوية، خصوصنًا في المراحل الأولى. وهذا يتفق مع ما أكد عليه تايلر ولي (Taylor \& Lee, 2012) من أن الإناث يتفوقن على الذكور في الفقرات المفتوحة الكما كما تفوقت

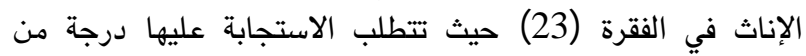

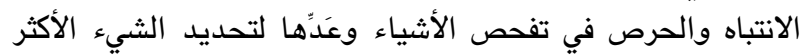

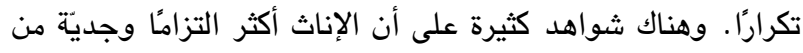

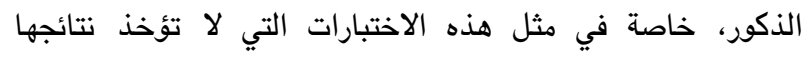

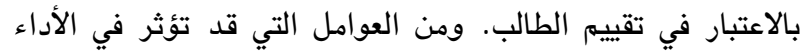

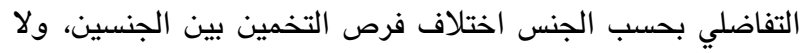

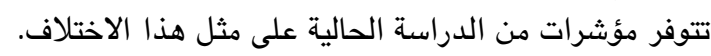

والجدير بالذكر أن العوامل التي نوقشت ليست عوامل سببية

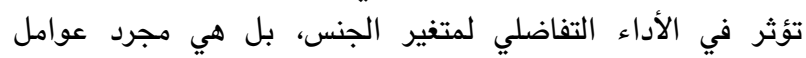

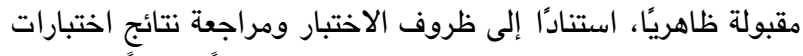

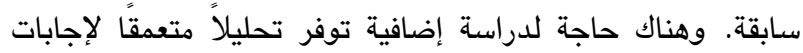
الطلبة لتوفير المزيد من الأدلة عن العوامل التي تؤثر في الأداء التفاضلي للفقرة.

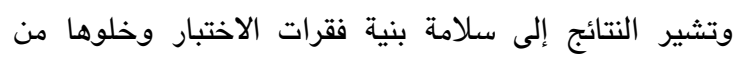

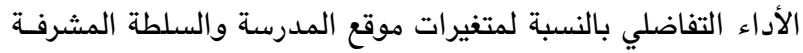

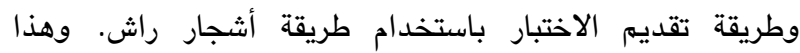


شجرة راث للكثف عن الأداء التفاضلي للفقرات بالنسبة لمتغيرات الدراسة للعينة الأولى (500 طالب وطالبة)

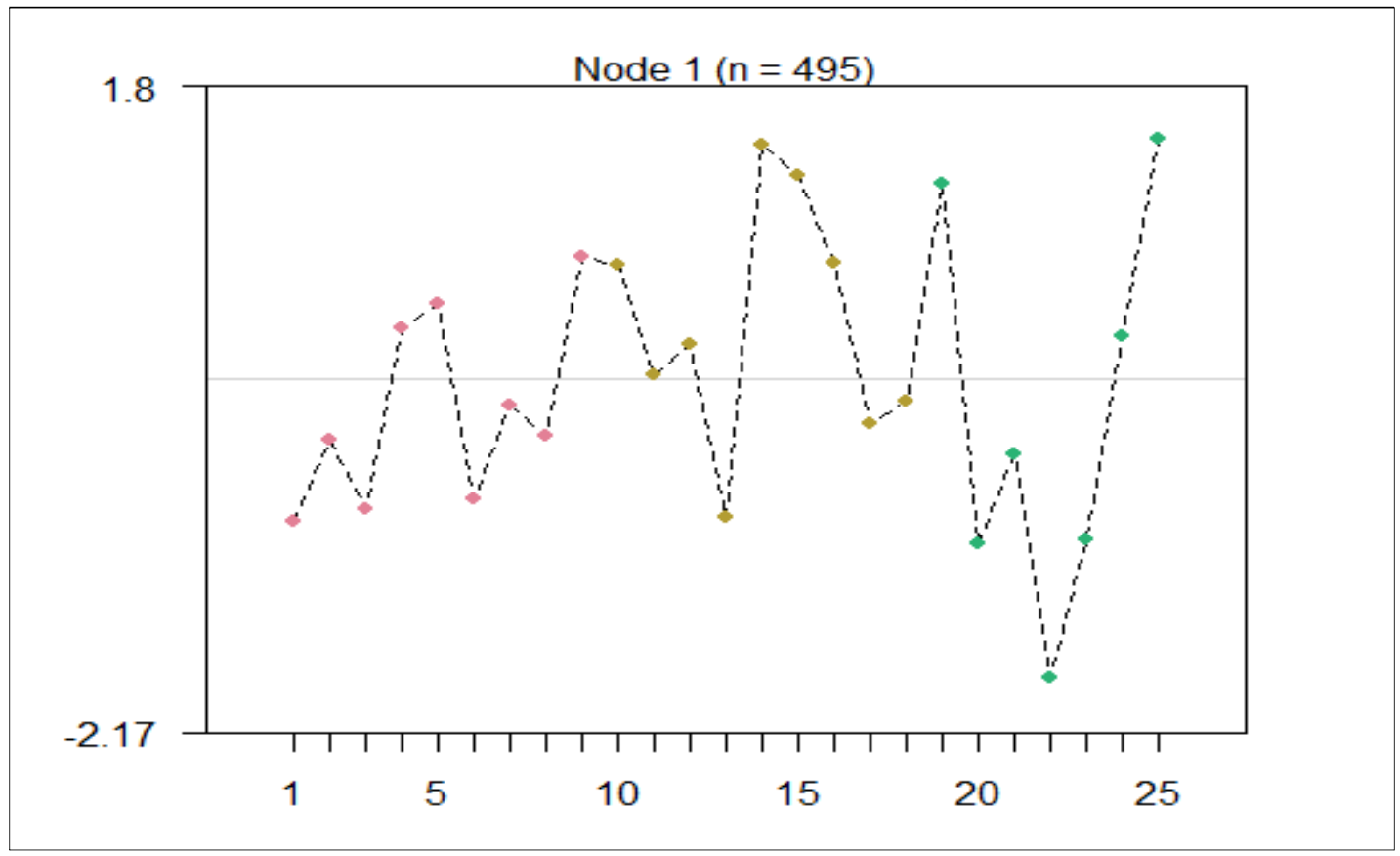

العينة الثانية: (2500) طالب وطالبة

يبين الشكل (4) شجرة راش للكثف عن الأداء التفاضلي

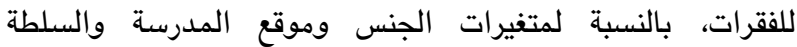
المشرفة وطريقة تقديم الاختبار للعينة الثانية (2500 طالب) .

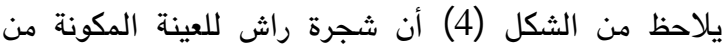

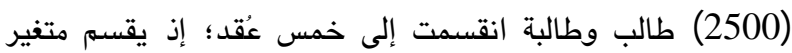

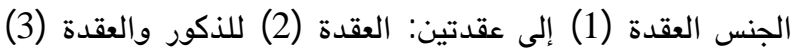

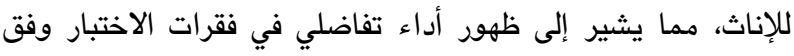

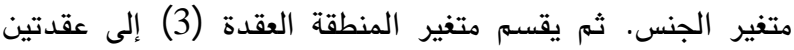

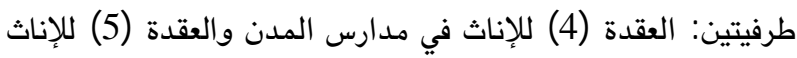

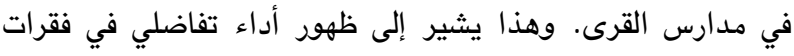

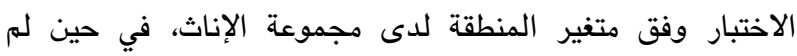

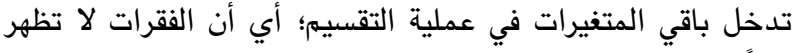

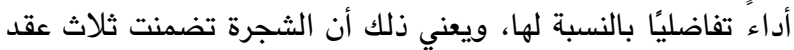

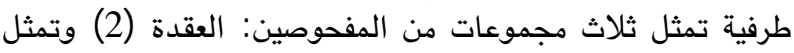

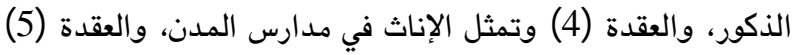

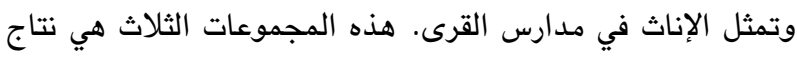

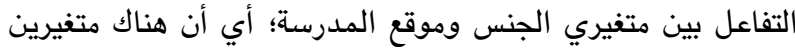

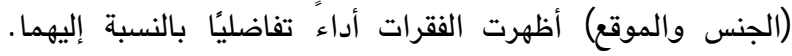

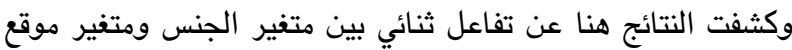

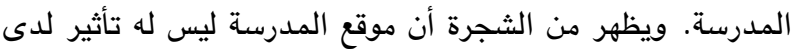
الذكور، بينما كان له تأثير لدى الإناث.
يلاحظ من الشكل (3) أن شجرة راش لم تنقسم نهائيًا،

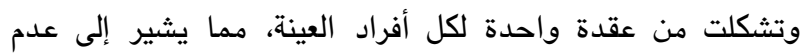

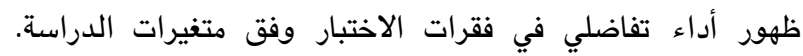

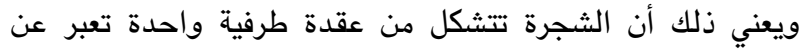

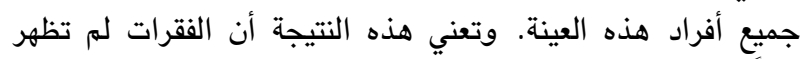

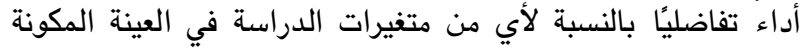

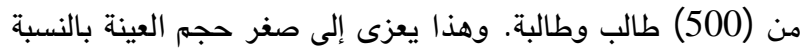

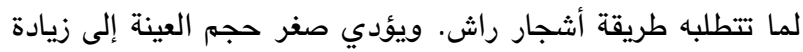

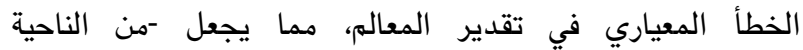

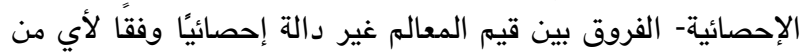

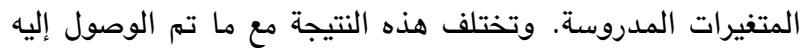
في السؤال الأول، حيث كان حجم العينة (1500) طالب وطالبة العالة.

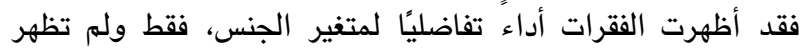

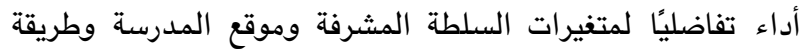

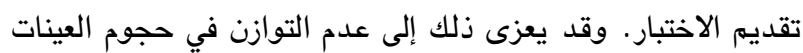

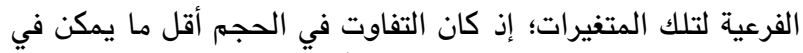

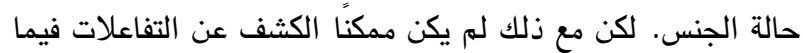

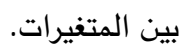


شجرة راث للكثف عن الأداء التفاضلي للفقرات بالنسبة لمتغيرات الدراسة للعينة الثانية (2500 طالب وطالبة)

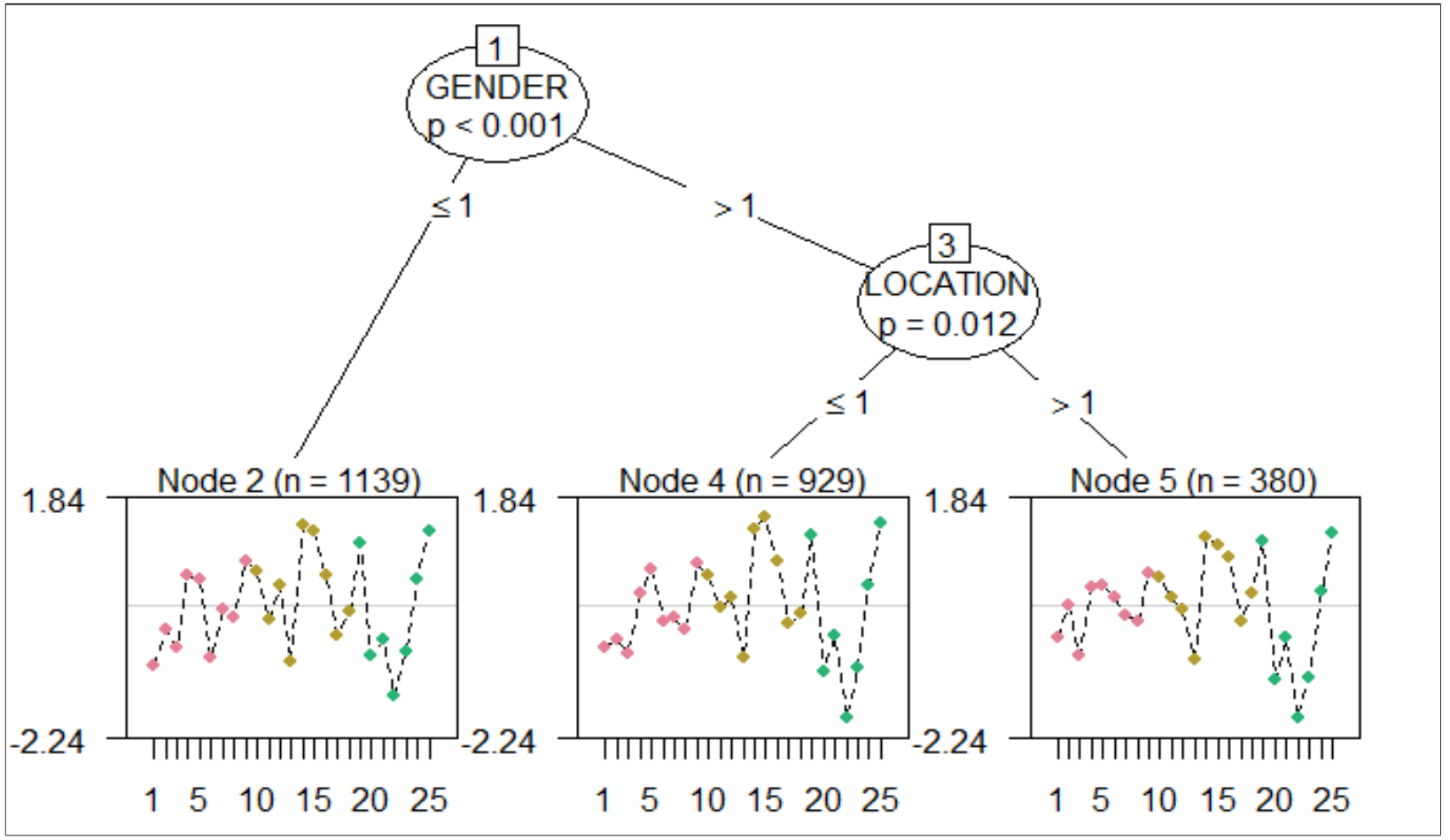

العينة الثالثة: (4000 طالب وطالبة)

يبين الشكل (5) شجرة راش للكثف عن الأداء التفاضلي للفقرات، بالنسبة لمتغيرات الدراسة للعينة المكونة من (4000) طالب وطالبة.

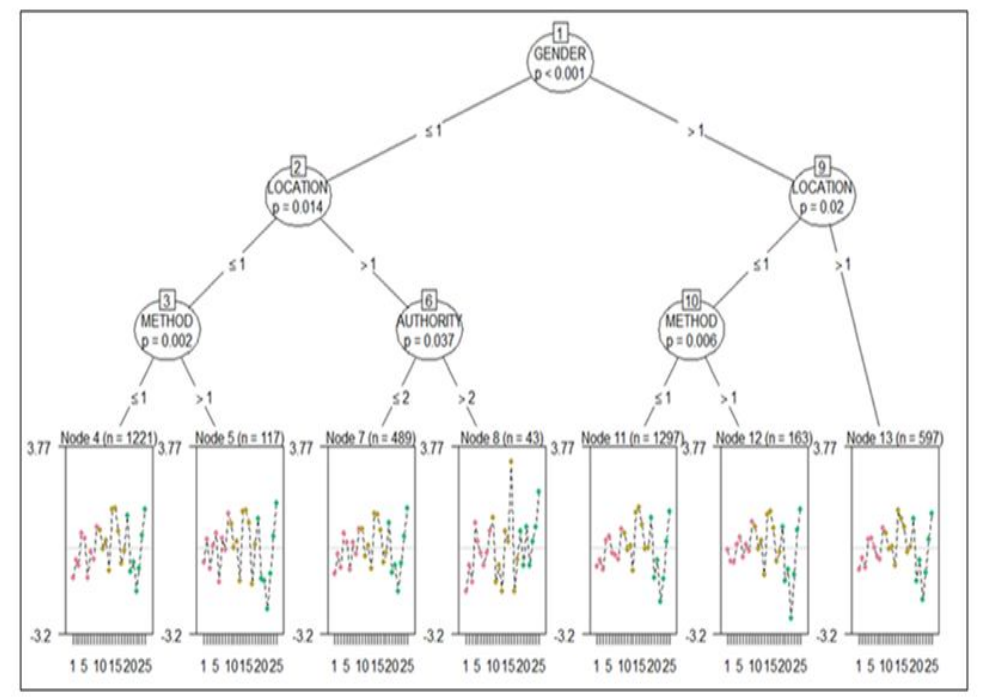

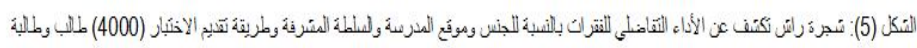

والعقدة (5) وتمثل الذكور في مدارس المدن الذين تقدموا

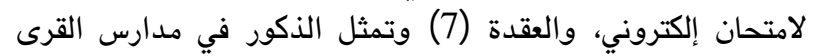

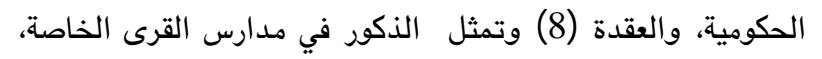

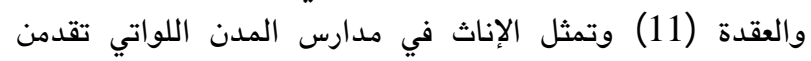
لامتحان ورقي، والعقدة (12) وتمثل الاناث في الإناث في مدارس المدن المدن

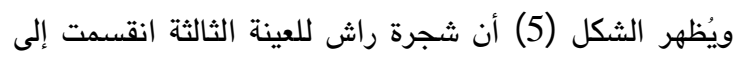

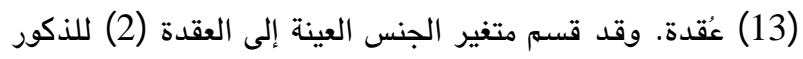

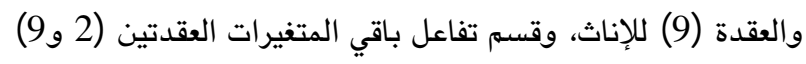

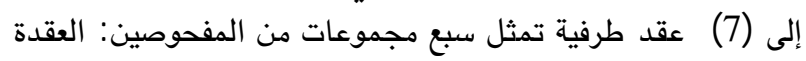
(4) وتمثل الذكور في مدارس المدن الذين تقدموا لامتحان ورقي، 
التي أظهرت حساسية طريقتي مانتل-هانزل ومنحنى خصائص الفقرة

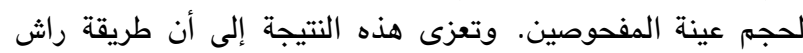

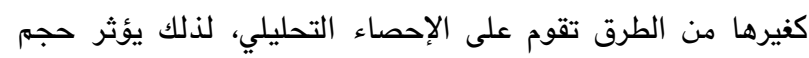

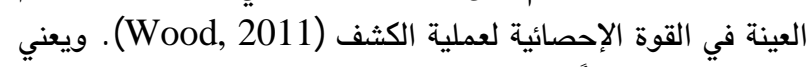

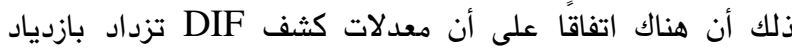

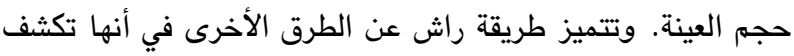

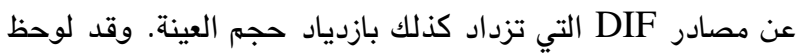

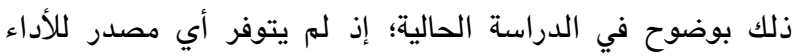
التفاضلي عند حجم عينة مقداره (500) طالب وطالب الب البة البة، وأصبح هناك أربعة مصادر عند حجم عينة مقداره (4000) طالب وطالبة.

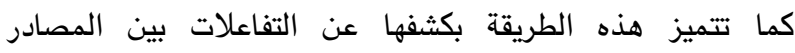

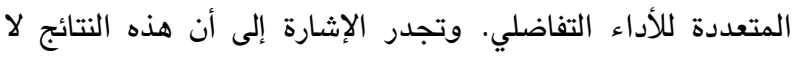

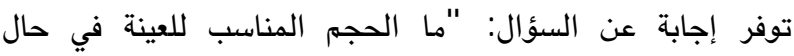

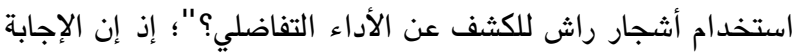

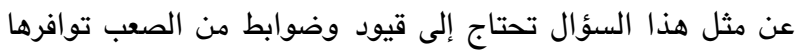

في الييانات الإمبريقية. التوصيات

في ظل التتائج التي توصلت إليها الدراسة الحالية، تمّ الخروج

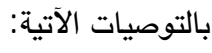

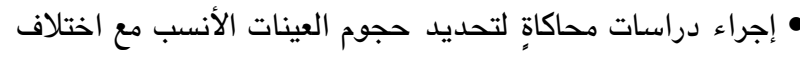
• عدد المتغيرات المستخدمة في التحليل.

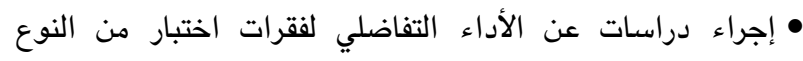

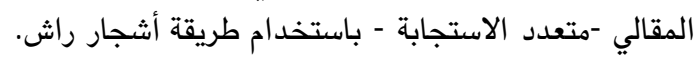

• زيادة الحرص في تدقيق ومراجعة فقرات الاختبار الوطني، خاصة أنها تطبق على عينة كبيرة من الطلبة.
اللواتي تقدمن لامتحان إلكتروني، والعقدة (13) وتمثل الإناث في

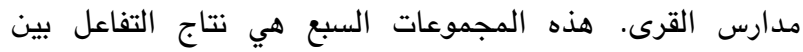

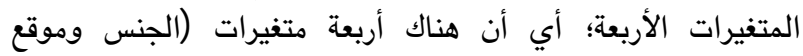

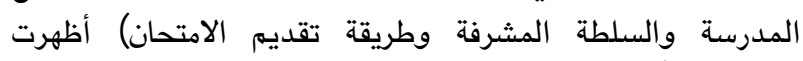

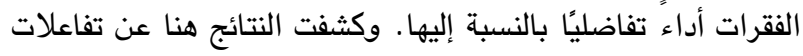
ثنائية وتفاعلات ثلاثية بين المتغيرات.

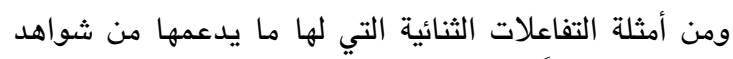

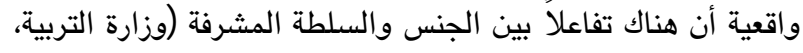

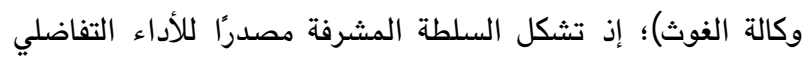

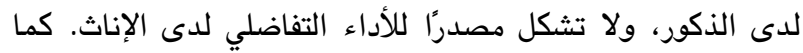

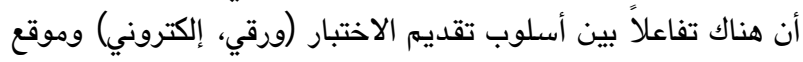

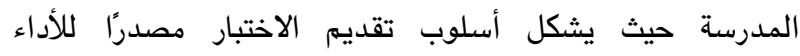

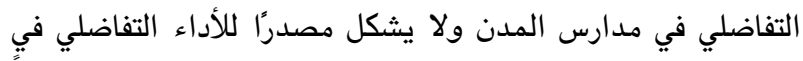

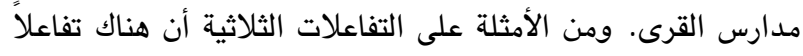

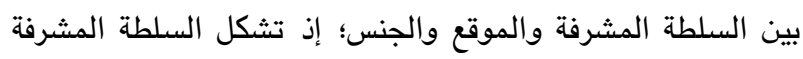

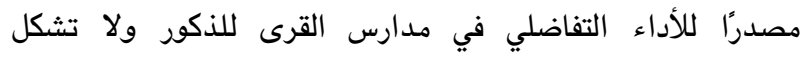

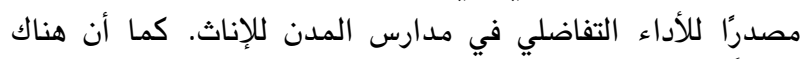

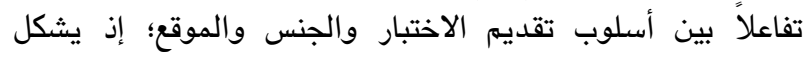

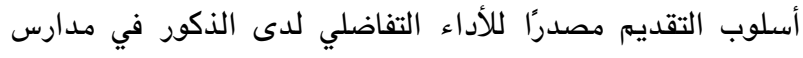
المدن ولا يشكل مصدرًا للأداء التفاضلي لدى الإناث في مدار الدور في مدارس

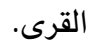

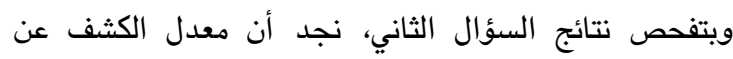

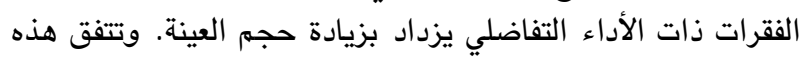

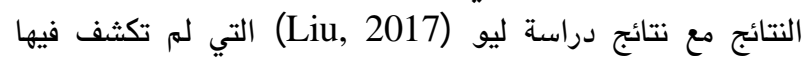

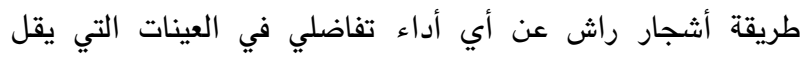

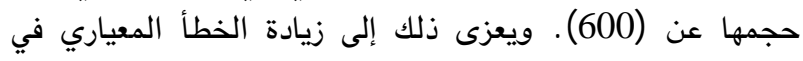

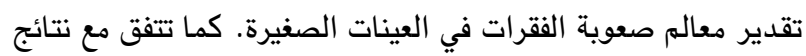
دراسة أبو شندي وكاظم (Abu Shindi \& Kazem, 2018) 


\section{References}

Abu Hammad, K. (2008). Investigating the effectiveness of item characteristic curve in detecting differential functioning according to gender in a selected sample from a mathematics test. Master Thesis, Yarmouk University. Irbid, Jordan.

Abu Shindi, Y. \& Kazem, A. (2018). Sex differential item functioning for mathematics test in a cognitive development program in the Sultanate of Oman by Mantel-Haenszel and item characteristic curve method. International Journal of Learning Management Systems, 6(2), 61-73.

Aladaileh, S. (1996). The influence of sex and educational level in confidence in learning mathematics and its relationship to academic achievement in mathematics for sixth and tenth grades in the government schools of Karak Governerate. Master Thesis, Mutah University, Al-Karak, Jordan.

Al Ajlouni, J. \& Sawalmeh, Y. (2016). Examining the differential distractors functioning of math test in the Jordanian national assessment of knowledge economy for sex and school location. An-Najah University Journal for Research, 30(11), 2265-2286.

Albano, A. D. \& Rodriguez, M. C. (2013). Examining differential math performance by gender and opportunity to learn. Educational and Psychological Measurement, 73(5), 836856.

Alomary, H. \& Shatnawi, A. (2016). Differential item functioning of the national education quality control test in mathematics for $10^{\text {th }}$ grade students according to gender. An-Najah University Journal for Research, 30(8),15291554.

Alpursan, I. (2013). Gender-related differential item fumctioning for Jordanian national test to control the quality of education in mathematics for $10^{\text {th }}$-grade students. Zagazig Journal, 28(79), 1-35.

Altarawneh, M. (2011). Investigating item bias in mathematics and science national tests for $8^{\text {th }}$ grade students. Master Thesis, Mutah University, Jordan.
Altıntaş, Ö. \& Kutlu, Ö. (2019). Investigating differential item functioning of Ankara University examination for foreign students by recursive partitioning analysis in the Rasch model. International Journal of Assessment Tools in Education, 6(4), 602-616.

Aryadoust, V. (2018). Using recursive partitioning Rasch trees to investigate differential item functioning in second-language reading tests. Studies in Educational Evaluation, 56, 197-204

Audeh, A. (2010). Measurement and evaluation in the teaching process ( $14^{\text {th }}$ ed.). Dar Al-Amal.

Boehmke, B. \& Greenwell, B. (2020). Hands-on machine learning with $R$. CRC Press.

Campbell, P. B. (1989). So, what do we do with the poor, non-white female? Issues of gender, race and social class in mathematics and equity. Peabody Journal of Education, 66(2), 95-112.

Chen, W. \& Thissen, D. (1997). Local dependence indices for item pairs using item response theory. Journal of Educational and Behavioral Statistics, 22(3), 265-289.

Ertuna, L. \& Gelbal. (2016). An application of differential item functioning analysis with Rasch trees. Retrieved from: https://www. researchgate.net/publication.

Frehat, N. (2014). differential item functioning of the national educational quality control test in mathematics and science for $10^{\text {th }}$ grade according to mode of test presentation. Ph.D. Dissertation, Yarmouk University, Irbid, Jordan.

Garner, M. \& Engelhard Jr, G. (1999). Gender differences in performance on multiple- choice and constructed response mathematics items. Applied Measurement in Education, 12(1), 2951.

Hattie, J. (1985). Methodology review: Assessing unidimensionality of tests and ltems. Applied Psychological Measurement, 9(2), 139-164.

Jordanian Ministry of Education. (2018). Results of the national educational quality control test in mathematics for the year 2017/2018. Amman, Jordan. 
Komboz, B., Strobl, C. \& Zeileis, A. (2018). Treebased global model tests for polytomous Rasch models. Educational and Psychological Measurement, 78(1), 128-166.

Kopf, J. (2013). Model-based recursive partitioning meets item response theory: New statistical methods for the detection of differential item functioning and appropriate anchor selection. PhD. Dissertation, University of München.

Liu, M. (2017). Differential item functioning in large-scale mathematics assessments: Comparing the capabilities of the Rasch trees model to traditional approaches. Ph.D. Dissertation, University of Toledo.

McGraw, R., Lubienski, S. T. \& Strutchens, M. E. (2006). A closer look at gender in NAEP mathematics achievement and affect data: Intersections with achievement, race/ethnicity and socioeconomic status. Journal for Research in Mathematics Education, 37(2), 129-150.

Reckase, M. D. (1997). The past and future of multidimensional item response theory. Applied Psychological Measurement, 21(1), 25-36.

Rover, C. (2005). That's not fair! Fairnees, bias \& differential item functioning in language testing. Retrieved from the University of Hawai'i Systm. Website: www.hawai'i.edu.

RTI International. (2012). Executive summary: Student performance in reading and mathematics, pedagogic practice, and school management in Jordan. USAID/Jordan.

Shea, C. A., (2013). Using a mixture IRT model to understand English learner performance on large-scale assessments. PhD. Ddissertation, University of Massachusetts, Amherst, MA.

Stoneberg Jr, B. D. (2004). A study of genderbased and ethnic-based differential item functioning (DIF) in the Spring 2003 Idaho standards achievement tests applying the simultaneous bias test (SIBTEST) and the Mantel-Haenszel chi square test. Retrieved from: https://eric.ed.gov/?id=ED489949.
Strobl, C., Kopf, J. \& Zeileis, A. (2010). A new method for detecting differential item functioning in the Rasch model. (Tech. Rep. No. 92). Department of Statistics at the University of Munich.

Strobl, C., Kopf, J. \& Zeileis, A. (2015). Rasch trees: A new method for detecting differential item functioning in the Rasch model. Psychometrika, 80(2), 289-316.

Taylor, C. S. \& Lee, Y. (2012). Gender DIF in reading and mathematics tests with mixeditem formats. Applied Measurement in Education, 25(3), 246-280.

Westers, P. \& Kelderman, H. (1992). Examining differential item functioning due to item difficulty and alternative attractiveness. Psychometrika, 57(1), 107-118.

Whitmore, M. L. (1995). A comparison of two differential item functioning detection methods: Logistic regression and analysis of variance approach using Rasch estimation. Ph.D. Dissertation, University of North Texas, Denton, TX.

Wood, S. (2011). Differential item functioning procedures for polytomous items when examinee sample sizes are small. Ph.D. Dissertation, University of Iowa, Iowa.

Zeileis, A., Hothorn, T. \& Hornik, K. (2008). Model-based recursive partitioning. Journal of Computational and Graphical Statistics, 17(2), 492-514.

Zhang, Y. (2001). Differential item functioning in a large-scale standardized mathematics assessment: The interaction of gender and ethnicity. PhD. Dissertation, Ohio Univer-sity, Athens, $\mathrm{OH}$. 